\title{
Changes in carbon flux and spectral reflectance of Sphagnum mosses as a result of simulated drought
}

Article

Accepted Version

Lees, K. J., Clark, J. M., Quaife, T., Khomik, M. and Artz, R. R. E. (2019) Changes in carbon flux and spectral reflectance of Sphagnum mosses as a result of simulated drought. Ecohydrology, 12 (6). e2123. ISSN 1936-0592 doi: https://doi.org/10.1002/eco.2123 Available at https://centaur.reading.ac.uk/84106/

It is advisable to refer to the publisher's version if you intend to cite from the work. See Guidance on citing.

To link to this article DOI: http://dx.doi.org/10.1002/eco.2123

Publisher: Wiley

All outputs in CentAUR are protected by Intellectual Property Rights law, including copyright law. Copyright and IPR is retained by the creators or other copyright holders. Terms and conditions for use of this material are defined in the End User Agreement.

www.reading.ac.uk/centaur 
Central Archive at the University of Reading

Reading's research outputs online 
Lees KJ (Orcid ID: 0000-0001-9254-2103)

\section{Changes in carbon flux and spectral reflectance of Sphagnum mosses as a result of simulated drought}

Lees KJ 1,2, Clark JM 1, Quaife T 3, Khomik M 4 \& Artz RRE 5

Corresponding author: k.lees@exeter.ac.uk

1. Department of Geography and Environmental Science, University of Reading, Whiteknights, Reading, RG6 6AB, UK

2. Department of Geography, University of Exeter, Streatham Campus, Exeter, EX4 4QE, UK

3. National Centre for Earth Observation, Department of Meteorology, University of Reading, Whiteknights Earley Gate, Reading, RG6 6BB, UK

4. Department of Geography and Environmental Management, University of Waterloo, 200 University Avenue West, Waterloo, ON, Canada N2L 3G1

5. The James Hutton Institute, Craigiebuckler, Aberdeen, AB15 8QH, Scotland

Running Head: Carbon flux and spectral reflectance of Sphagnum mosses under drought.

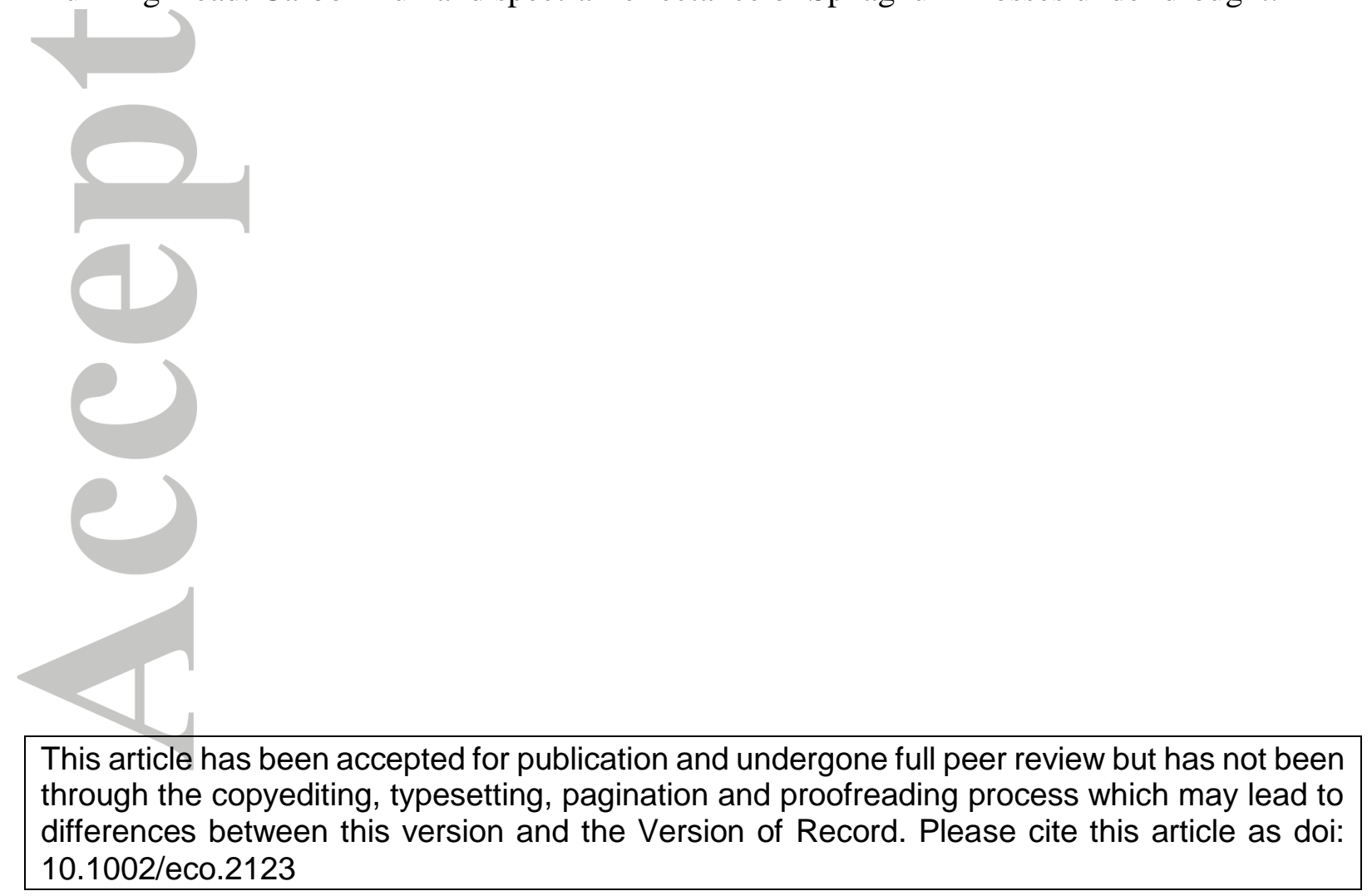




\section{$\underline{\text { Abstract }}$}

Sphagnum is an important peat-forming genus which aids the carbon sequestration of peatlands. Sphagnum is sensitive to drought, however, and it is uncertain how well it can recover from long periods without rainfall. Spectral reflectance can be used to assess Sphagnum desiccation damage, and we also tested whether it can be used to detect recovery. Different rainfall simulations were applied to two species of Sphagnum to assess the impact of drought on carbon function. After eighty days all samples were rewetted to assess recovery. The rainfall simulations included inputs analogous to actual precipitation at the field site (Forsinard Flows reserve, Northern Scotland), potential future changes in rainfall, and extended total drought. During the experiment Gross Primary Productivity (GPP) and respiration were measured. Photosynthesis decreased after approximately 30 days of continuous drought (ie. days without rain). Spectral reflectance was measured to assess Sphagnum bleaching. The spectral absorption feature of Sphagnum associated with red light (around $650 \mathrm{~nm}$ ) was affected by drought, and did not recover after rewetting during the experimental period. No significant difference was found between the two Sphagnum species studied with respect to their photosynthesis or respiration, but there was a significant difference in optimum water content and spectral reflectance between the two. The results from this study suggest that Sphagnum carbon function is resilient to quite long drought periods, but once damage has occurred recovery is likely to be difficult. The spectral reflectance of Sphagnum can give useful information in assessing whether significant desiccation damage has occurred.

Keywords (not included in title)

Desiccation, peatlands, Gross primary productivity, respiration, water content, NDVI 1.Introduction

Sphagnum moss is an important peat-forming genus, and is instrumental in the sequestration of carbon in Northern ombrotrophic peatlands. The function of peatlands as a carbon sink is of interest to policy makers, as peatland restoration can now be claimed as a carbon abatement in national accounting under the Kyoto Protocol (Hiraishi et al., 2014).

Drought has been shown in previous studies to affect Sphagnum function (Bragazza, 2008; Clymo, 1973; Harris, 2008; Strack \& Price, 2009; Van Gaalen, Flanagan, \& Peddle, 2007), and this could become important as climate change increases the frequency of occurrence of hotter, dryer summers (Jenkins et al., 2010; Hoegh-Guldberg, Jacob, \& Taylor, 2018). It is uncertain, however, how long and how extreme drought needs to be before it affects Sphagnum function (Bragazza, 2008). It is also unclear whether, and to what extent, Sphagnum can recover its functionality after desiccation. Some studies suggest that desiccated Sphagnum can recover its carbon function after a period of rewetting (McNeil \& Waddington, 2003; Robroek et al., 2009), whilst others suggest that extreme desiccation may be irreversible (Bragazza, 2008; Schipperges \& Rydin, 1998).

Frequent small precipitation events can relieve the effects of drought on carbon function by rewetting the moss capitula (Nijp et al., 2014; Robroek et al., 2009). There is also some 
evidence that the frequency of rainfall events is more important than the overall water input due to the inability of Sphagnum to draw water up from a deep water table (Adkinson \& Humphreys, 2011; Nijp et al., 2014; Robroek et al., 2009; Strack \& Price, 2009). Raindays are considered particularly important, and the temporal distribution of precipitation has been shown to be more important than total amounts in terms of maintaining carbon function (Backeus, 1988; Lindsay et al., 1988).

Spectral reflectance can provide information about Sphagnum health, including carbon functioning under water limitation (Harris, 2008; Letendre et al., 2008; Van Gaalen et al., 2007). Certain areas of the reflectance spectrum of Sphagnum moss indicate water content, chlorophyll, and plant health. This could be a useful way to detect the impact of drought on Sphagnum's carbon functioning when direct measurements are unavailable. The Normalised Vegetation Index (NDVI) which we consider in this study is a widely used spectral index that can be easily calculated from satellite or UAV (Unmanned Aerial Vehicle) data. Validation of this in the laboratory is particularly useful for researchers using remote sensing over peatlands at large scales (Lees et al., 2018).

In this study five experimental water input regimes were set up in the laboratory to test the relative impacts of different rainfall amounts and frequencies on Sphagnum carbon dioxide gas exchange. Different Sphagnum species may react differently to low water contents, with hummock-growing species being more tolerant to drought conditions than species which grow closer to the water table (Harris, 2008; Robroek et al., 2009; Strack and Price, 2009). Two Sphagnum species, Sphagnum capillifolium (a hummock-forming species) and Sphagnum papillosum (a lawn-preferring species), are compared to assess whether different Sphagnum species have differing responses to drought stress. In this work we are particularly seeking to address how drought stress affects the carbon function (photosynthesis and respiration) of Sphagnum samples, and whether this functioning recovers after a rewetting event. Finally, we also consider the changes in spectral reflectance in Sphagnum during drought stress, as this may be a useful way to assess Sphagnum health using remote sensing.

We hypothesise that (1) water content reduction will lead to a decrease in photosynthesis and respiration, but that this may be ameliorated by more frequent water input, and that the carbon function will recover after rewetting. (2) S. papillosum will be more sensitive to drought than $S$. capillifolium, with a higher optimum water content and less resilience to water reduction as it prefers slightly wetter microhabitats (Robroek et al., 2009); and (3) that changes in spectral reflectance will correlate well with changes in Sphagnum carbon function during the experiment.

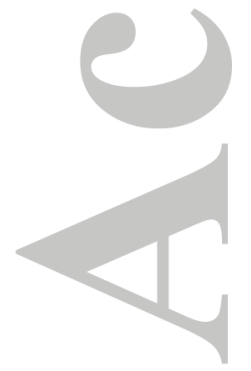

This article is protected by copyright. All rights reserved. 


\section{Method}

\subsection{Sphagnum species}

Our study sites were located at the Royal Society for the Protection of Birds (RSPB) Forsinard Flows reserve in Northern Scotland (58.3552, -3.9993 to 58.4458, -3.6972

WGS84). Parts of the reserve are undergoing restoration from forest to bog and were at different stages of restoration at the time of sampling. The samples collected for our lab study were collected from three areas of the reserve, known as Talaheel (58.4116, -3.7992 WGS84), Catanach (58.4020, -3.7130 WGS84), and Raphan (58.4109, -3.7318 WGS84).

S. capillifolium and S. papillosum were selected as two contrasting Sphagnum species (see Figure 1). S. capillifolium is red to green and grows in tightly packed clusters with a 'pompom' appearance due to its hemi-spherical capitulum (Laine et al., 2009). S. papillosum is green to yellow-brown and grows in carpets and low hummocks often interspersed with other species. S. capillifolium is a hummock-forming species, whilst $S$. papillosum prefers slightly wetter conditions and is often found in lawns and occasionally in ditches (Hayward and Clymo, 1983, 1982).

\subsection{Experimental set-up}

Samples of Sphagnum moss ( $6 \mathrm{~cm}$ deep and $10 \mathrm{~cm}$ diameter, $\mathrm{n}=20$ of each species) were collected by cutting around and below white plastic tubing of these dimensions. The samples were kept moist in a coolbox whilst being transported between the field sites and the laboratory. When the samples first arrived in the laboratory they were inundated with deionised water and the excess drained off to bring them to saturation. Once in the lab the samples were placed in 1 litre, straight-sided, clear polycarbonate jars and stored in a growth cabinet (Panasonic MLR-352H-PE) on a 12-hour day and night cycle.

The average climate of the Forsinard Flows reserve was used to set growth cabinet conditions. Climate averages were estimated from records of four surrounding weather stations from 1981-2010: Wick John O Groats Airport, Kinbrace, Altnaharra SAWS, and Strathy East (Met Office, 2018). Conditions from April to September were considered (see Figure 2). The average daily maximum temperature for the four sites over those 6 months ranged from 10.4 to $17.1^{\circ} \mathrm{C}$, and the average daily minimum ranged from 2.7 to $9.8^{\circ} \mathrm{C}$. The average relative humidity was approximately $80 \%$ (Met Office, 2018). During the day the growth cabinet was kept at maximum light levels $(20,000 \mathrm{~lx}) 15^{\circ} \mathrm{C}$, and $70 \%$ relative humidity (slightly lower than the average at the site to aid drying of samples). At night the cabinet was dark, at $5^{\circ} \mathrm{C}$, and the humidity was unregulated.

The samples were left in the growth cabinet and watered regularly with de-ionised water (40 $\mathrm{ml}$, equating to $5 \mathrm{~mm}$, every 2 days to maintain saturation) for a week prior to beginning the experiment to allow them to acclimatise. During the experiment, the samples were moved around within the cabinet in order to minimise edge effects. Within the cabinet there were three shelves; all samples within each group (A to E, see section 2.3.1.) were kept together on the same shelf, but the groups were moved to different shelves every measurement day, and 
the samples within each group were moved around randomly in relation to each other every watering day.

\subsection{Experimental procedure}

\subsubsection{Rainfall simulations}

The conditions in the growth cabinet were kept the same as described above. Five different rainfall simulations were designed to represent a range of rainfall conditions at the site. Four replicates of each species were exposed to each regime.

The average rainfall (April-September, 1981-2010) was $66 \mathrm{~mm}$ per month, with 13 raindays per month (Met Office, 2018). 13 raindays a month is approximately the same as watering three times per week, and this was set as the steady-state watering schedule. $66 \mathrm{~mm}$ divided by 13 raindays gives an approximate input of $5 \mathrm{~mm}$ per rainday. However, when this was trialled during the acclimatisation period it caused an increase in water levels rather than a steady-state (shown by an increase in weight), and so the input was halved to approximately $2.5 \mathrm{~mm}(20 \mathrm{ml})$ per sample per rainday. This lower steady-state input was needed to account for missing water fluxes that would be observed in the field, including vertical and lateral drainage into the peat, vascular plant competition, and run-off. Under experimental simulations, all water input into the samples in the laboratory was kept within the jars and could only be used by the Sphagnum. Deionised water was used for rainfall simulations to maintain consistency with previous studies (Clark et al., 2012, 2006) administered by drips using a laboratory wash bottle.

Rainfall simulation treatment followed a factorial design. There were five treatment groups, each comprising four samples of each Sphagnum species. The precipitation treatments used were: two different precipitation amounts, two different frequencies. In addition, we included continuous drought (see Table 1). Group A was designated as the control group, as the samples were given $20 \mathrm{ml}$ of water three times per week, the amount required to maintain steady-state water content. These treatment regimes were maintained until drought effects were observed in the carbon flux and spectral reflectance results (see Section 2.3.2.). This process took twelve weeks.

After the first three weeks (a time period of total drought which we would expect to show visible change in the field, Bragazza, 2008) little effect was observed in carbon flux.

Therefore, to increase the intensity of the experimental simulation, the humidity in the growth cabinet was reduced to 55\% (the minimum the cabinet was able to regulate), in order to dry the samples as much as possible. This is lower than would be found under normal conditions at the field sites (approx. 80\%), but was used to encourage faster drying of the samples. In field conditions there would be higher evapotranspiration due to wind, even at higher humidities, so this drop in experimental humidity compensated for the lack of air movement in the growth cabinet. 
After the rainfall simulations had been run for 12 weeks total, all the samples were flooded to within $2 \mathrm{~cm}$ of the top of the clear plastic jars to simulate total rewetting. Complete inundation was used to simulate rewetting following a period of drought or limited rainfall. The Sphagnum samples in their plastic collars floated at the surface of the water, meaning that although they were inundated they still had contact with the air. They were kept in the cabinet (70\% humidity) for one month whilst inundated, in order to assess recovery following full rewetting. Rochefort, Campeau and Bugnon (2002) found that a month of inundation will not harm Sphagnum, and may even encourage growth. After one month all excess water was drained, and the carbon flux measurements were repeated three times over a week to compare dynamics with drought and pre-drought conditions.

\subsubsection{Measurements}

Three times per fortnight (after watering of sets A-D) the net carbon fluxes of all the samples (groups A-E) were measured. The flux measurements were taken using a LICOR-8100 infrared gas analyser (LICOR Inc., Lincoln, Nebraska, USA), connected to a custom-built clear plastic chamber. Each sample was brought out of the growth cabinet and placed under a high pressure sodium growth lamp (Philips Belgium 9M SON-T-AGROO 400) in a laboratory in order to keep light levels as constant as possible (at 55,500 lm) The clear chamber was placed over the sample using a foam seal in between the sample container and chamber, and a measurement taken of the net carbon flux for 90 seconds. The chamber was removed from the sample to allow ventilation, and a blackout cloth cover was then placed over the chamber and another measurement taken to get the respiration flux. Gross Primary Productivity (GPP) was calculated as the difference between the light and dark chamber measurement values. The time the samples spent out of the growth cabinet was minimised as much as possible in order to reduce the effects of variable air temperature and relative humidity (the longest any sample spent outside the cabinet was ten minutes maximum). The order in which samples were measured was randomised to minimise background effects.

To reduce the effect of varying background light levels (due to working in a laboratory with access to natural light) a PAR sensor was added to the experimental set-up four weeks in to the experiment, and calculations were applied to remove the effect of background light levels on GPP. This adaptation was made after viewing preliminary data. Measurements taken in the first four weeks were corrected based on time of measurement. Given that the measurements were taken at regular intervals over the course of the mornings, time was used as a proxy from PAR in the correction calculations for the data from the first four weeks. Variations in background light levels due to cloud cover are not accounted for in the first four weeks of results (See Appendix 1 for fuller explanation).

Samples were weighed three times a week before and after watering throughout the experiment. At the end of the experiment samples were dried in a laboratory oven at $70^{\circ} \mathrm{C}$ for 72 hours and the dry weights collected in order to retrospectively calculate moisture contents. All water contents are given in grams of fresh weight divided by grams of dry weight $(\mathrm{g} / \mathrm{g})$.

The spectral reflectance was measured using a Ger3700 spectrometer (Geophysical and Environmental Research corp., 1999) mounted in a dark room with a single constant light 
source (1000 W high-intensity halogen lamp at an angle of $45^{\circ}$ and a distance of $0.5 \mathrm{~m}$ ). Each sample was placed under the spectrometer and a measurement taken; the sample was then rotated and another measurement taken, and rotated again for a third measurement. The average of these three spectra was taken to compensate for potential structural effects. A spectralon reference panel was used to take reference spectra between samples. The sample and reference panel were viewed at nadir $\left(90^{\circ}\right)$.

The red absorption feature in the reflectance spectra was found to be a good indicator of drought stress (see Section 3.2.), and the Normalised Difference Vegetation Index (NDVI) was used to measure this effect across the experiment. The NDVI is calculated as:

$\mathrm{NDVI}=\left(\mathrm{R}_{\mathrm{NIR}}-\mathrm{R}_{\mathrm{red}}\right) /\left(\mathrm{R}_{\mathrm{NIR}}+\mathrm{R}_{\mathrm{red}}\right)$

The red and NIR bands were calculated by averaging the reflectance values for $630-680 \mathrm{~nm}$ and $845-885 \mathrm{~nm}$ respectively.

\subsubsection{Statistical analysis}

All statistical analysis was done using RStudio (R Core Team, 2017). In order to create a robust statistical analysis of this experiment, the first three measurement days (day 1 to 10) were averaged into a result category 'start', the last three days of the water input regimes (day 71 to 80 ) were averaged into 'end', and the three measurements after rewetting (day 113 to 120) were averaged into 'rewetted'. The effect of Group and Species on each of the four measured variables (Water content, GPP, R, and NDVI) was analysed for each of the three time period results.

In each case the Fligner-Killeen test for equal variance was performed, as this test is robust when using non-normally distributed data. A two-way ANOVA was performed for Species and Group effects in order to assess interactions. The normality of the ANOVA residuals was assessed visually and using the Shapiro-Wilks test.

Two Kruskal-Wallis tests, one with Species and one with Group as the independent variable, were used. Post-hoc testing using Dunn's test was done with the PMCMRplus package (Pohlert, 2018). Kruskal-Wallis is a non-parametric equivalent to a one-way ANOVA, and as such should account for the non-normal distribution and unequal variances which were found to be a feature of some of the data.

In order to consider the relationships between measured variables we subtracted all results for each sample from the first measurement made of that sample; this made relationships clearer to interpret, and minimised autocorrelation from repeated measurements. To determine the optimum water content for Sphagnum GPP a quadratic model was fitted to the data and solved for the vertex. A linear model was fitted to analyse the relationship between GPP and NDVI. 


\section{$\underline{\text { 3.Results }}$}

\subsection{Carbon function and water content}

Overall patterns in the experiment were as follows. We found that water, GPP and respiration decreased across the water input regimes period for the water-limited groups C, D and E (see Figures $3 \& 4$ ). After rewetting the water content of all groups recovered, but the GPP of drought group E did not recover (Figure 3). The results show that there was no significant species effect at any point during the experiment on water content, GPP, or respiration (details of statistical test results are given in Appendix 2).

Water content of the Sphagnum ranged from 12.8 to $38.4 \mathrm{~g} / \mathrm{g}$ in all samples pre-treatment, and from 1.2 to $3.3 \mathrm{~g} / \mathrm{g}$ in the total drought group $\mathrm{E}$ at the end of the treatment period. Figure 3 shows the changes in water content for the five groups. The water content was relatively constant for $\mathrm{A}$ and $\mathrm{B}$, as expected because of the rainfall input, although the average water contents for group B (averaging $29.2 \mathrm{~g} / \mathrm{g}$ ) appeared higher than group A (averaging $22.4 \mathrm{~g} / \mathrm{g}$ ) across the whole experiment. Groups C, D, and E showed decreases by the end of the watering regimes period, with the decrease greatest in group E (drought group). Rewetting increased the water content of all groups (to a mean water content across all groups of 29.9 $\mathrm{g} / \mathrm{g})$.

GPP ranged from 0.39 to $2.10 \mathrm{umol} / \mathrm{m}^{2} / \mathrm{s}$ in all samples pre-treatment, and from 0.39 to 1.07 $\mathrm{umol} / \mathrm{m}^{2} / \mathrm{s}$ in group $\mathrm{E}$ at the end of the treatment period. Figure 3 shows the changes in GPP for each of the five treatment groups. The GPP of all samples decreased over the watering regimes period. The decrease of the control samples (group A) is a statistically significant $(\mathrm{p}<0.05)$, although very small (a slope of -0.0039), trend across the 80-day period. This decrease may be due to a lack of nutrients, as de-ionised water was all that they received and blanket bogs receive their nutrient inputs from precipitation.

At the end of the water input regimes period the GPP of group E $\left(0.70 \mathrm{umol} / \mathrm{m}^{2} / \mathrm{s}\right)$ was highly significantly different to the GPP of group D $\left(1.12 \mathrm{umol} / \mathrm{m}^{2} / \mathrm{s}, \mathrm{p}<0.05\right)$, and moderately significantly different to the GPP of groups A and C $\left(1.06,1.07 \mathrm{umol} / \mathrm{m}^{2} / \mathrm{s}, \mathrm{p}<0.1\right)$. After rewetting the GPP of group E was significantly different to all other groups $\left(0.26 \mathrm{umol} / \mathrm{m}^{2} / \mathrm{s}\right.$, compared to 0.88 to $1.00 \mathrm{umol} / \mathrm{m}^{2} / \mathrm{s}, \mathrm{p}<0.05$, see Figure 3 ).

Respiration varied from 0 to $1.44 \mathrm{umol} / \mathrm{m}^{2} / \mathrm{s}$ in all samples pre-treatment, and from 0 to 0.45 $\mathrm{umol} / \mathrm{m}^{2} / \mathrm{s}$ in group $\mathrm{E}$ at the end of the treatment period. Figure 3 shows the respiration results for the five groups. Respiration for groups A-D stayed constant, whilst E showed a slight decrease towards the end of the 80 day experimental period, and then after rewetting a sharp increase. At the end of the water input period group $\mathrm{E}\left(0.25 \mathrm{umol} / \mathrm{m}^{2} / \mathrm{s}\right)$ was significantly different to groups A, C and D $\left(0.80,0.85,0.75 \mathrm{umol} / \mathrm{m}^{2} / \mathrm{s}, \mathrm{p}<0.05\right)$.

The ratio of GPP:R was similar throughout the first 80 days, with Group A ranging from 0.40 to 2.84 and averaging 1.56 (see Figure 3). Group B shows slightly higher ratios generally due to slightly lower respiration values. Group E shows a large range in ratios at the end of the water input period, partly due to the small values of both GPP and R, and a decrease after rewetting due to the higher respiration values. 
Figure 4 shows the change in GPP in each group across the water input period. It can be seen that the GPP mean of group E is below the GPP means of all other groups from day 29 onwards (with the exception of day 47 when the mean is similar to group B). Due to the large range relative to absolute values in GPP for all groups across the period, Group E is not consistently significantly different from the other groups, but the days when the difference is significant are more frequent in the second half of the period.

Figure 5 (top) shows that the relationship between water content and GPP corresponds to a quadratic model. The optimum of $S$. capillifolium is $-7.6 \mathrm{~g} / \mathrm{g}$ change, whilst for $S$. papillosum it is $3.1 \mathrm{~g} / \mathrm{g}$ change. By selecting all values less than $1 \mathrm{~g} / \mathrm{g}$ different to the starting water content of the samples, we can calculate the starting water content for GPP for $S$. capillifolium as $23.4 \mathrm{~g} / \mathrm{g}$ (16.5 to 29.5), and for S. papillosum as $24.4 \mathrm{~g} / \mathrm{g}$ (12.6 to 38.4). Therefore, the optimum water content for $S$. capillifolium is $15.8 \mathrm{~g} / \mathrm{g}(8.9$ to $21.9 \mathrm{~g} / \mathrm{g}$ ) and for S. papillosum it is $27.5 \mathrm{~g} / \mathrm{g}(15.7$ to $41.5 \mathrm{~g} / \mathrm{g})$.

Figure 5 (bottom) shows the significant linear relationship $\left(\mathrm{R}^{2}=0.13, \mathrm{p}<0.05\right)$ between respiration and GPP in our Sphagnum moss samples across the water input period.

\subsection{Spectral reflectance}

The drying effect on Sphagnum reflectance was visible to the naked eye. Both species showed bleaching as the experiment progressed (see Figure 6), due to an increase in reflectance in all optical wavelengths (see Figure 7), although the effect was more pronounced in S. capillifolium.

Spectral data from the two Sphagnum species were significantly different $(\mathrm{p}<0.05)$ throughout the experiment, as shown in Figure 8, with $S$. capillifolium having higher NDVI results than S. papillosum. Water-limited groups C, D and E all showed a decrease in NDVI across the water input period (Figure 9$)$, but only group E (0.32) showed a significant difference to control group A $(0.64)$ at the end of the period $(<0.05$, statistical results given in Appendix 2). After rewetting the NDVI of these three groups recovered slightly, but the NDVI of group E (0.41) was still significantly different to all other groups $(p<0.05)$.

Figure 10 considers the relationship between change in GPP and change in NDVI, and shows that the relationship is significant for group $\mathrm{E}$ in both species, and for groups $\mathrm{C}$ and $\mathrm{D}$ in $S$. capillifolium only. We also tested the relationship between GPP and NDVI for each species at the start and end of the water input regimes to test whether the NDVI can detect differences in photosynthetic capacity between samples, but none of the relationships were significant at the $\mathrm{p}<0.05$ level.

\section{$\underline{\text { 4.Discussion }}$}

The NDVI paralleled differences in GPP, and also showed a species effect. GPP and NDVI of group E did not recover after rewetting. The greatest effect of water stress on Sphagnum spp. studied here was in colour changes that could be seen by eye in terms of bleaching and quantified using spectral data and indices. Spectral data shows that the red absorption zone (630-680 nm) detected drought stress effects in Sphagnum moss. At the end of the watering regime period the NDVI could detect a difference between group $\mathrm{E}$ and the control group $\mathrm{A}$. 
This suggests that NDVI is a useful tool for monitoring Sphagnum drought stress. Bubier, Rock and Crill (1997) recognised that their samples which had been dried and rehydrated had shallower chlorophyll absorption features (at $660 \mathrm{~nm}$ ) than fresh samples, but did not consider the significance of this in terms of plant function indexes. Van Gaalen, Flanagan and Peddle's (2007) laboratory study, however, did not show significant changes in the red absorption feature when their samples were dried to approx. $5 \mathrm{~g} / \mathrm{g}$, suggesting either that water content needs to be below this to show change in this region of the spectrum, or that their experiments were on too short a timescale (hours rather than weeks) to cause measurable damage to Sphagnum chlorophyll function.

In terms of the relationship between optical measures of Sphagnum health by NDVI and its photosynthetic performance measured by GPP, the range of change in GPP associated with little change in NDVI (see Figure 9) in groups A and B for both species suggests that NDVI was only sensitive to change in GPP due to drought stress in this experiment and not due to other causes. As the other factors influencing GPP were kept as constant as possible in this experiment, it is likely that the large range in GPP in groups A and B is primarily due to natural fluctuation in photosynthesis. Harris (2008) completed a laboratory study comparing photosynthetic efficiency (measured using chlorophyll fluorescence, $\Phi_{\text {PSII }}$ ) of water limited Sphagnum mosses to spectral indexes. In agreement with the current work, Harris' (2008) study found that the NDVI gave a strong positive correlation with the photosynthetic efficiency of all samples pooled ( 0.68 correlation). This study found a correlation of 0.58 between NDVI and GPP for all samples in drought group E.

Our results suggest that a period of at least 29 days is required to affect Sphagnum carbon function (photosynthesis and respiration). This result might, however, be different in field conditions as there are several factors which we did not replicate in the lab, for example wind increasing evapotranspiration, peat presence affecting water availability and drainage, and the composition of rainwater. In August 1995 there was a period of 21 days when only $1 \mathrm{~mm}$ of rainfall fell at Altnaharra meteorological station, suggesting that this length of drought is possible but very rare (Met Office, 2012). However, the UKCP09 report (Jenkins et al., 2010) suggests a $50 \%$ chance of $20 \%$ lower summer rainfall in their higher emissions scenario for the Forsinard Flows area by 2080 . This increases the possibility of a long drought period occurring in the future, which could have a negative impact on Sphagnum function, and ultimately the presence of blanket bog in this area (Clark et al., 2010).

Our study found that the water effect on GPP corresponded to a quadratic curve, with different parameters for the two species tested. Optimum water content for S. capilifollium and S. papillosum was found to be $15.8 \mathrm{~g} / \mathrm{g}$ and $27.5 \mathrm{~g} / \mathrm{g}$ respectively. Optimum water contents for photosynthesis reported in the literature vary (see Table 2); Adkinson and Humphreys (2011) suggested an optimum water content of 5-13 g/g at their Canadian peat bog site in hummock species, whilst Schipperges and Rydin (1998) suggested an optimum range of water contents $400-2500 \%$ of dry weight within the capitula (approx. equal to 6-27 $\mathrm{g} / \mathrm{g}$ using values from our study for comparison), and McNeil and Waddington (2003) gave an optimum of 11.3 to $26.7 \mathrm{~g} / \mathrm{g}$ in the moss cushion. Robroek et al. (2009) noted the point at which water content causes a decrease in GPP to be between approx. 15-25 g/g, whilst Van 
Gaalen et al. (2007) found that GPP decreased above 9 and below $8 \mathrm{~g} / \mathrm{g}$ dry weight using shallow Sphagnum teres mats. Adkinson and Humphreys (2011) found that GPP decreased below capitula water content of $5 \mathrm{~g} / \mathrm{g}$ in a field experiment at their Canadian peat bog site. The optimum water contents found in the current study are within the range given by previous studies, and show a lower optimum water content for $S$. capillifolium, the hummockforming species. Studies considering larger Sphagnum samples generally seem to give higher optimum water contents than those studying individual capitula, likely due to pockets of water held within the Sphagnum cushion.

We did not find that water input frequency had an effect on carbon function. Group B (full water, half days) showed higher than average water contents and lower than average GPP and respiration at points throughout the experiment. It may be the case that, as measurements were taken within 12 hours of all samples being watered, the samples in group B were often above optimum water content on measurement days. However, as there are almost no significant differences in measured variables between groups $C$ and $D$ we cannot say that the different rainfall frequencies tested in this experiment have a lasting impact.

The decrease and increase in respiration of extreme drought group E suggests two different effects. Firstly, the significant decrease in respiration during the watering regimes period of the experiment concurs with the GPP results suggesting a loss of plant function during this period. The literature agrees that Sphagnum respiration also decreases under drought, but apparently at a slower pace than GPP (Schipperges and Rydin, 1998; Adkinson and Humphreys, 2011). The ratio of GPP:R in the current work is similar at the start and end of the period (although the range is greater at the end due to generally smaller values and large variation in both GPP and respiration), suggesting that the change in respiration is strongly linked to the change in GPP.

Secondly, we suggest that the sudden increase in group E respiration after rewetting may be due to the presence of slime mould or other microorganisms which were decomposing the dead Sphagnum matter; slime was observed on several of the samples in group E after rewetting. An increase in these microorganisms could cause an increase in respiration such as was measured (Schipperges and Rydin, 1998; Robroek et al., 2009). Adkinson and Humphreys (2011) found the compensation point (when GPP=R and NEE=0) to be $5 \mathrm{~g} / \mathrm{g}$, whilst Schipperges and Rydin (1998) found it to be 100-225\% (approx. equal to 3.4-3.8 g/g). In contrast, we found that respiration in group E decreased at roughly the same rate as GPP and the ratio GPP:R remained similar (see Figure 3), which means that compensation point was only reached after rewetting when there was a spike in $\mathrm{R}$ and very low GPP.

Several previous studies have assessed the effects of rewetting desiccated Sphagnum (see Table 2). In this study we rewetted the desiccated Sphagnum for 30 days, but there was little sign of recovery in the GPP of group E. Group E NDVI values were also significantly different to all other groups, despite the values of $\mathrm{C}$ and $\mathrm{D}$ recovering to the level of $\mathrm{A}$ and $\mathrm{B}$ after rewetting. Schipperges and Rydin (1998) found that totally desiccated (capitula below $100 \%$ ) Sphagnum did not recover after rewetting, although their study did not allow much time (12 hours) for rewetting and recovery. In contrast, Robroek et al. (2009) found that their Sphagnum samples were assimilating carbon after 16 days of high water table following 23 
days of drought treatment, but not to the extent of pre-drought treatment assimilation. The lowest water content reached in their experiment was approximately $6 \mathrm{~g} / \mathrm{g}$, however, compared to this study which reached an average of $2.2 \mathrm{~g} / \mathrm{g}$ in group $\mathrm{E}$ by the end of the 80 days drying. McNeil and Waddington (2003) found that in Sphagnum which had been dried to 6\% Volumetric Moisture Content (VMC) (approximately the same as our samples reached) photosynthesis recovered after 20 days of saturation. Nijp et al. (2014) found that S. fuscum (hummock species) recovered after 11 days rewetting following 17 days drought, but hollowpreferring species did not recover to pre-desiccation levels after rewetting. Van Gaalen et al. (2007) found that Sphagnum respiration increased after rewetting but GPP remained lower than initial values, in agreement with this work. Wagner \& Titus (1984) found that S. fallax was more tolerant of drought periods than $S$. nemoreum, despite preferring wetter microhabitats. Both species showed slow and limited recovery after more than five days of total drought.

Figure 8 shows that although the NDVI values did increase somewhat after rewetting, it was not enough to restore them to pre-experimental levels. This agrees with the GPP of Group E showing little recovery after rewetting. The loss of the red light absorption feature in group $\mathrm{E}$ samples, both before and after rewetting, indicates a significant loss of plant function. It is likely that a breakdown of plant cells during extreme desiccation leads to a decrease in carbon function which is either entirely irreversible, or certainly slow to recover. Future studies should consider monitoring desiccated Sphagnum for longer time periods after rewetting to monitor if recovery occurs, and how long it takes.

In this study, although the majority of the Sphagnum cushion depth was kept in the samples, the removal of the upper parts of the plant from the basal stem held in the peat may have affected desiccation progress and recovery. Water table movements within the peat can have an effect on Sphagnum desiccation (Ketcheson \& Price, 2014; Moore \& Waddington, 2015; Weber et al., 2017), and it is possible that Sphagnum left in situ would have greater resilience. Removal of part of the moss cushion could also have increased desiccation from the edges by removing contact with surrounding moss (Robroek et al., 2007). Future work on intact Sphagnum in a peatland environment would be very useful in furthering this research.

The lack of difference in GPP, respiration or water content between the two species, $S$. capillifolium and S. papillosum, was somewhat surprising. The different environments of the two species would suggest that $S$. papillosum, a lawn-preferring species, would be less tolerant to drought than $S$. capillifolium, a hummock-forming species. This difference between hummock and hollow species was suggested by Harris (2008) and Strack and Price (2009), although as both these studies only used one sample of each species it may be that this was a sample-specific difference rather than a species-specific response. Titus et al. (1983) found the opposite effect between two Sphagnum species which preferred different microhabitats; they showed that $S$. fallax, although growing closer to the water table than $S$. nemoreum, actually functions better at low water contents. S. nemoreum was shown to have a higher water-holding capacity and more effective capillary transport (Titus and Wagner, 1984). 
It may be the case that the habitats of the two species used in this study, $S$. capillifolium and S. papillosum, are too similar to show differential responses to moisture content, although the difference in optimum water contents was clear. Robroek et al. (2009) found a speciesspecific difference in carbon assimilation response to water table change in a large study using S. magellanicum (S. medium), S. cuspidatum and S. rubellum. Schipperges and Rydin (1998) tested the response of individual Sphagnum capitula of various species to desiccation, and found that those species with a compact growing structure survived drought better than those with a loose growing structure. S. capillifolium would be in the former category and $S$. papillosum in the latter, but this had no effect in our experiment. There was however, a significant difference between species NDVI values, possibly due to the naturally red colouring of $S$. capillifolium. More work should be done into the response of NDVI to drought stress in mixed Sphagnum moss species, and in combination with other plants under field conditions.

We found that there was no difference in water content or carbon function between species, and that water input frequency did not have a clear impact on carbon function. Water input amount did have a clear effect, and drought group E was significantly different to control group A in all measured factors at the end of the 80 days. Nijp et al. (2014) and Robroek et al. (2009) found that rainfall frequency affected carbon fluxes during dry conditions (defined as water table more than $15 \mathrm{~cm}$ below surface, and $10 \mathrm{~cm}$ below surface, respectively), but not during wet conditions (defined as optimum for each species, and $1 \mathrm{~cm}$ below surface, respectively), and it may be the case that the conditions which groups $\mathrm{A}$ to $\mathrm{D}$ were subjected to were never extreme enough for precipitation frequency to have an impact. Future work in this area should measure carbon fluxes both before and after experimental watering, and also explore small water input impacts on Sphagnum which has been subjected to prolonged drought.

\section{$\underline{\text { 5. Conclusions }}$}

We conclude that Sphagnum capillifolium and Sphagnum papillosum from blanket bogs are resilient to long (approx. 30 days) drought periods, but once prolonged drought affects carbon function significantly, recovery is difficult. The effect of long drought periods can be seen in the red zone of the reflectance spectra of Sphagnum, meaning that the NDVI has potential to provide useful information about Sphagnum carbon function. The GPP and NDVI of severely desiccated Sphagnum did not recover with rewetting, indicating that such spectral indices are not only useful for detecting contemporary water limitation damage, but also the longer term effects of such periods even after water tables have risen. The success of the NDVI in matching the GPP results from group $\mathrm{E}$ is encouraging for researchers who use spectral indices to gain information about peat bogs from remote sensing. The NDVI is widely used as a method of estimating plant health from remote sensing (Lees et al., 2018), and our work with Sphagnum proves that this index can be a useful tool in peat bog ecosystems, particularly in hot and dry seasons when drought damage is predicted. 


\section{Acknowledgements}

Thanks are due to the Forsinard Flows RSPB reserve for allowing us to collect Sphagnum samples for this work, and also to Stephen Fry and Vicky Russell at the Chobham Common NNR for allowing us to collect a few Sphagnum samples for sampling and storage methods testing. Thanks to Mike Lees for making the 40 Sphagnum sample collars. Thanks to Mhairi Coyle for reviewing the manuscript, and to the two anonymous reviewers for their helpful comments.

Authors' contributions

KJL led the experimental work of this project, the data analysis, and the drafting of the manuscript. JMC contributed particularly to the experiment design and statistical analysis of the study, and RREA was instrumental in site selection and sample collection. All authors on this manuscript critically reviewed the work and provided valuable input to data interpretation.

The authors state that there are no conflicts of interest.

\section{Funding}

Kirsten Lees was part funded by a studentship from The James Hutton Institute, and part funded by the Natural Environment Research Council (NERC) SCENARIO DTP (Grant number: NE/L002566/1). Tristan Quaife was funded by the NERC National Centre for Earth Observation (NCEO; NE/R016518/1). Myroslava Khomik and Rebekka Artz were funded by The Scottish Government Strategic Research Programme 2016-2021.

\section{$\underline{\text { Data archive statement }}$}

All data used in this study is archived in The Environmental Information Data Centre held by the Centre for Ecology and Hydrology (Lees et al., 2019).

\section{$\underline{\text { References }}$}

Adkinson, A.C., Humphreys, E.R., 2011. The response of carbon dioxide exchange to manipulations of Sphagnum water content in an ombrotrophic bog. Ecohydrology 4, 733-743. https://doi.org/10.1002/eco.171

Backeus, I., 1988. Weather variables as predictors of Sphagnum growth on a bog. Ecography (Cop.). 11, 146-150. https://doi.org/10.1111/j.1600-0587.1988.tb00793.x

Bragazza, L., 2008. A climatic threshold triggers the die-off of peat mosses during an extreme heat wave. Glob. Chang. Biol. 14, 2688-2695. https://doi.org/10.1111/j.13652486.2008.01699.x

Bubier, J.L., Rock, B.N., Crill, P.M., 1997. Spectral reflectance measurements of boreal wetland and forest mosses. J. Geophys. Res. Atmos. 102, 29483-29494. https://doi.org/10.1029/97JD02316 
Clark, J., Gallego-Sala, A., Allott, T., Chapman, S., Farewell, T., Freeman, C., House, J., Orr, H., Prentice, I., Smith, P., 2010. Assessing the vulnerability of blanket peat to climate change using an ensemble of statistical bioclimatic envelope models. Clim. Res. 45, 131-150. https://doi.org/10.3354/cr00929

Clark, J.M., Chapman, P.J., Heathwaite, A.L., Adamson, J.K., 2006. Suppression of dissolved organic carbon by sulfate induced acidification during simulated droughts. Environ. Sci. Technol. 40, 1776-83.

Clark, J.M., Heinemeyer, A., Martin, P., Bottrell, S.H., 2012. Processes controlling DOC in pore water during simulated drought cycles in six different UK peats. Biogeochemistry 109, 253-270. https://doi.org/10.1007/s10533-011-9624-9

Clymo, R.S., 1973. The growth of Sphagnum: some effects of environment, Source: Journal of Ecology.

Geophysical and Environmental Research corp., 1999. GER 3700 User Manual Release 2.1. Milbrook, New York.

Harris, A., 2008. Spectral reflectance and photosynthetic properties of Sphagnum mosses exposed to progressive drought. Ecohydrology 1, 35-42. https://doi.org/10.1002/eco.5

Hayward, P.M., Clymo, R.S., 1983. The Growth of Sphagnum: Experiments on, and Simulation of, Some Effects of Light Flux and Water-Table Depth. J. Ecol. 71, 845. https://doi.org/10.2307/2259597

Hayward, P.M., Clymo, R.S., 1982. Profiles of Water Content and Pore Size in Sphagnum and Peat, and their Relation to Peat Bog Ecology. Proc. R. Soc. B Biol. Sci. 215, 299325. https://doi.org/10.1098/rspb.1982.0044

Hiraishi, T., Krug, T., Tanabe, K., Srivastava, N., Jamsranjav, B., Fukuda, M., Troxler, T., 2014. Revised Supplementary Methods and Good Practice Guidance Arising from the Kyoto Protocol.

Hoegh-Guldberg, O., Jacob, D., Taylor, M., 2018. Chapter 3: Impacts of $1.5^{\circ} \mathrm{C}$ global warming on natural and human systems.

Jenkins, G., Murphy, J., Sexton, D., Lowe, J., Jones, P., Watson, R., Scientific Advisor, C., 2010. UK Climate Projections: Briefing report Foreword from Professor.

Ketcheson, S.J., Price, J.S., 2014. Characterization of the fluxes and stores of water within newly formed Sphagnum moss cushions and their environment. Ecohydrology 7, 771782. https://doi.org/10.1002/eco.1399

Laine, J., Helsingin yliopisto. Metsäekologian laitos., 2009. The intricate beauty of Sphagnum mosses : a Finnish guide for identification. Department of Forest Ecology, University of Helsinki.

Lees, K.J., Quaife, T., Artz, R.R.E., Khomik, M., Clark, J.M., 2018. Potential for using remote sensing to estimate carbon fluxes across northern peatlands - A review. Sci. 
Total Environ. 615, 857-874. https://doi.org/10.1016/J.SCITOTENV.2017.09.103

Lees, K.J., Clark, J.M., Quaife, T., Artz, R.R.E., Khomik, M., Ritson, J. 2019. Peatland vegetation: field and laboratory measurements of carbon dioxide fluxes and spectral reflectance . NERC Environmental Information Data Centre. Available online at: https://doi.org/10.5285/ab9f47f9-9faf-4403-a57e-25e31f581ed0

Letendre, J., Poulin, M., Rochefort, L., 2008. Sensitivity of spectral indices to $\mathrm{CO}_{2}$ fluxes for several plant communities in a Sphagnum -dominated peatland. Can. J. Remote Sens. 34, S414-S425. https://doi.org/10.5589/m08-053

Lindsay, R.A., Charman, J., Everingham, F., O’reilly, R.M., Palmer, M.A., Rowell, T.A., Stroud, D.A., Ratcliffe, D.A., Oswald, P.H., 1988. The Flow Country - The peatlands of Caithness and Sutherland.

McNeil, P., Waddington, J.M., 2003. Moisture controls on Sphagnum growth and CO 2 exchange on a cutover bog. J. Appl. Ecol. 40, 354-367.

Met Office, 2018. Altnaharra SAWS climate information - Met Office [WWW Document]. URL https://www.metoffice.gov.uk/public/weather/climate/gfkgdgj2j (accessed 7.9.18).

Met Office, 2012. Met Office Integrated Data Archive System (MIDAS) Land and Marine Surface Stations Data (1853-current).

Moore, P.A., Waddington, J.M., 2015. Modelling Sphagnum moisture stress in response to projected 21st-century climate change. Hydrol. Process. 29, 3966-3982. https://doi.org/10.1002/hyp.10484

Nijp, J.J., Limpens, J., Metselaar, K., van der Zee, S.E.A.T.M., Berendse, F., Robroek, B.J.M., 2014. Can frequent precipitation moderate the impact of drought on peatmoss carbon uptake in northern peatlands? New Phytol. 203, 70-80. https://doi.org/10.1111/nph.12792

Pohlert, T., 2018. PMCMRplus: Calculate Pairwise Multiple Comparisons of Mean Rank Sums Extended. R package version 1.2.0.

R Core Team, 2017. R: A language and environment for statistical computing.

Robroek, B.J.M., Limpens, J., Breeuwer, A., Ruijven, J. van, Schouten, M.G.C., 2007. Precipitation determines the persistence of hollow Sphagnum species on hummocks. Wetlands 27, 979. https://doi.org/10.1672/0277-5212(2007)27[979:pdtpoh]2.0.co;2

Robroek, B.J.M., Schouten, M.G.C., Limpens, J., Berendse, F., Poorter, H., 2009. Interactive effects of water table and precipitation on net $\mathrm{CO}_{2}$ assimilation of three co-occurring Sphagnum mosses differing in distribution above the water table. Glob. Chang. Biol. 15, 680-691. https://doi.org/10.1111/j.1365-2486.2008.01724.x

Rochefort, L., Campeau, S., Bugnon, J.-L., 2002. Does prolonged flooding prevent or enhance regeneration and growth of Sphagnum? Aquat. Bot. 74, 327-341. https://doi.org/10.1016/S0304-3770(02)00147-X 
Schipperges, B. $\square$ B., Rydin, $\square \square \square$ H, 1998. Response of photosynthesis of Sphagnum species from contrasting microhabitats to tissue water content and repeated desiccation. New Phytol 140, 677-684.

Strack, M., Price, J.S., 2009. Moisture controls on carbon dioxide dynamics of peatSphagnum monoliths. Ecohydrology 2, 34-41. https://doi.org/10.1002/eco.36

Titus, J.E., Wagner, D.J., 1984. Carbon Balance for Two Sphagnum Mosses: Water Balance Resolves a Physiological Paradox. Ecology 65, 1765-1774.

https://doi.org/10.2307/1937772

Titus, J.E., Wagner, D.J., Stephens, M.D., 1983. Contrasting Water Relations of Photosynthesis for Two Sphagnum Mosses. Ecology 64, 1109-1115. https://doi.org/10.2307/1937821

Van Gaalen, K.E., Flanagan, L.B., Peddle, D.R., 2007. Photosynthesis, chlorophyll fluorescence and spectral reflectance in Sphagnum moss at varying water contents. Oecologia 153, 19-28. https://doi.org/10.1007/s00442-007-0718-y

Wagner, D.J., Titus, J.E., 1984. Comparative desiccation tolerance of two Sphagnum mosses. Oecologia 62, 182-187. https://doi.org/10.1007/BF00379011

Weber, T.K.D., Iden, S.C., Durner, W., 2017. Unsaturated hydraulic properties of Sphagnum moss and peat reveal trimodal pore-size distributions. Water Resour. Res. 53, 415-434. https://doi.org/10.1002/2016WR019707 


\section{Appendix 1 - Correcting for background light effects}

When it became apparent that background light levels were affecting the carbon flux results, a PAR sensor was added to the Licor-8100, and PAR measurements were recorded for each net carbon flux measurement (NEE). Sample CapA1 (a sample of S. capillifolium from control group A) was selected as a control, and 11 measurements of NEE and PAR were taken across the course of a morning, approximately every 25 minutes from $8.30 \mathrm{am}$ to 12 noon. This was repeated with eight other randomly selected samples (covering both species and different stages of dryness) in the next few weeks of the experiment. The results are shown in Figure A1 and Table A1. It can be seen that for all the samples tested, the GPP was increasing with PAR.

It is likely that each sample would have a different response curve to PAR, and that this might change with water content. Unfortunately time constraints meant that we could not create an individual response line for each sample on each day, so we compromised by using an averaged response line.

A PAR to GPP regression is normally a response curve but the low light levels in this experiment meant that the saturation point was not reached and so a linear regression was appropriate. The intercept value is unimportant as it was applied equally across all samples. The slope value is the focus here. The average slope value was 0.0204 , so the regression equation used was:

$$
\text { GPPr }=0.0204 \times \text { PAR }
$$

The correction applied to the GPP measurements was then:

$\mathrm{GPP}=\mathrm{GPPm}-\mathrm{GPPr}+1.4$

Where GPPm is the measured GPP from the chamber fluxes, and GPPr is the estimated GPP from the regression line.

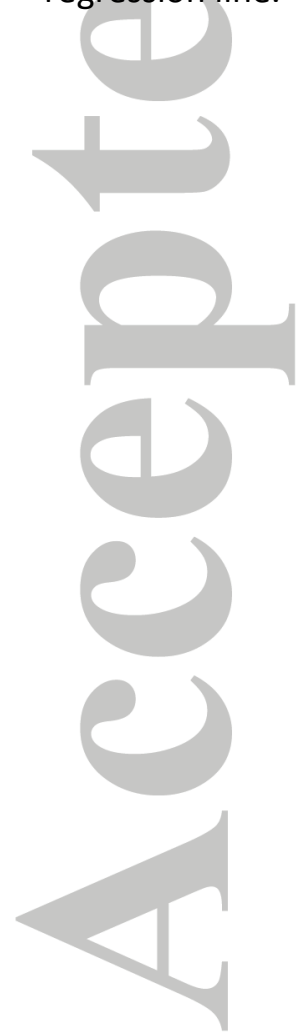

This article is protected by copyright. All rights reserved. 


\section{GPP relationship to PAR}

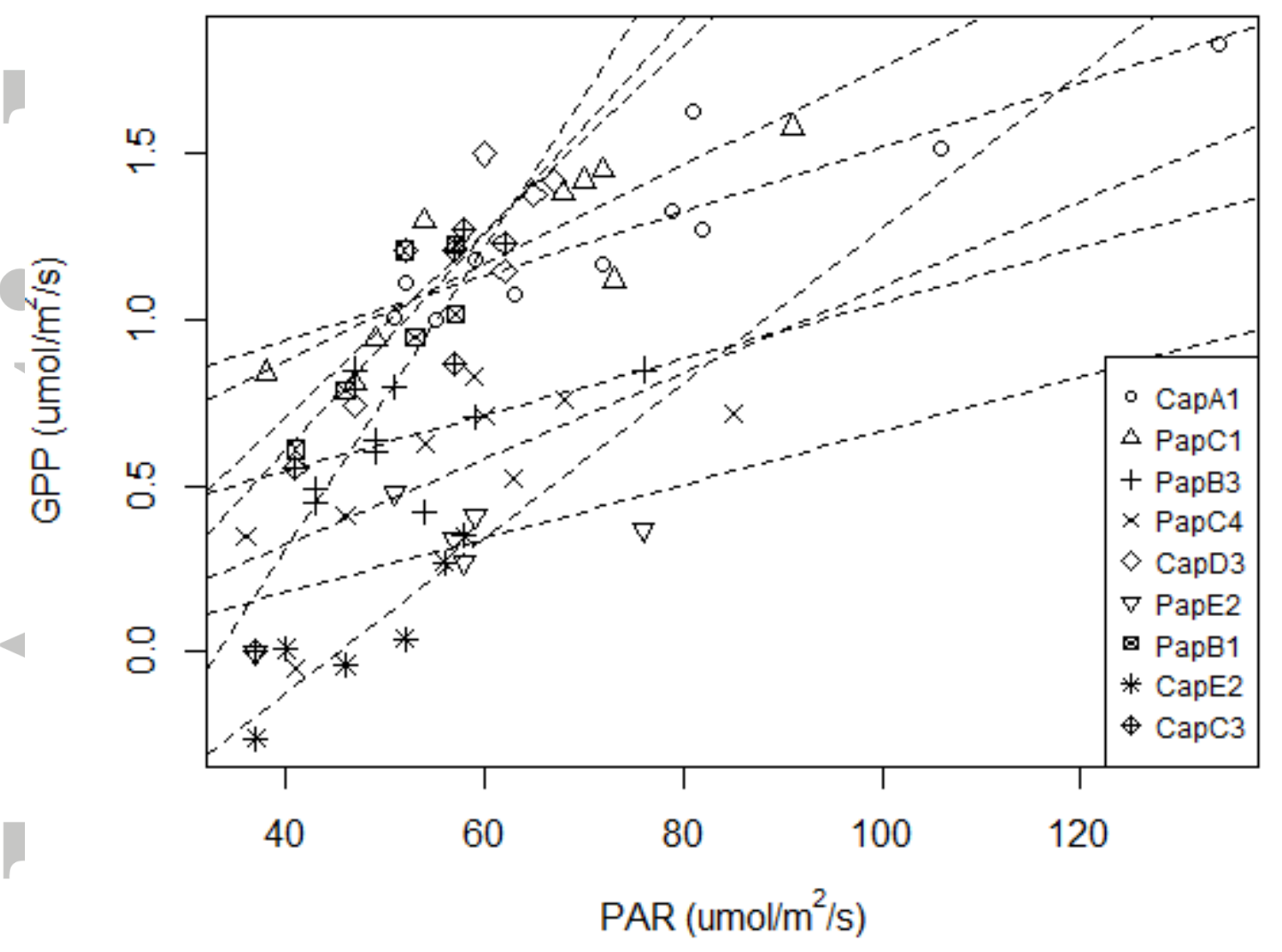

Figure A1-GPP related to PAR for nine different Sphagnum samples.

Table A1-Each sample tested for PAR:GPP relationship, as shown in Figure A1. This table gives the slope of the regression line for each sample, the correlation between the PAR and GPP values, and the number of measurements taken.

\begin{tabular}{|l|l|l|l|}
\hline & slope & correlation & no. of measurements \\
\hline PapC1 & 0.00148 & 0.86 & 9 \\
\hline CapC3 & 0.00455 & 0.96 & 6 \\
\hline PapB1 & 0.003247 & 0.86 & 6 \\
\hline PapC4 & 0.001292 & 0.7 & 9 \\
\hline PapB3 & 0.000844 & 0.51 & 9 \\
\hline PapE2 & 0.000811 & 0.61 & 6 \\
\hline CapE2 & 0.002336 & 0.91 & 6 \\
\hline CapA1 & 0.000967 & 0.91 & 11 \\
\hline CapD3 & 0.002798 & 0.79 & 6 \\
\hline
\end{tabular}

As the first four weeks of the experiment did not have attached PAR data, it was necessary to find a proxy correction method. The timing of the NEE measurements was considered a proxy for PAR, because the main changes in background light were seen across the mornings as the sun rose. Cloud 
cover changes had some effect on PAR, but these were minimal in comparison with the increasing PAR across the mornings. Figure A2 and Table A2 show the models used.

\section{GPP relationship to time}

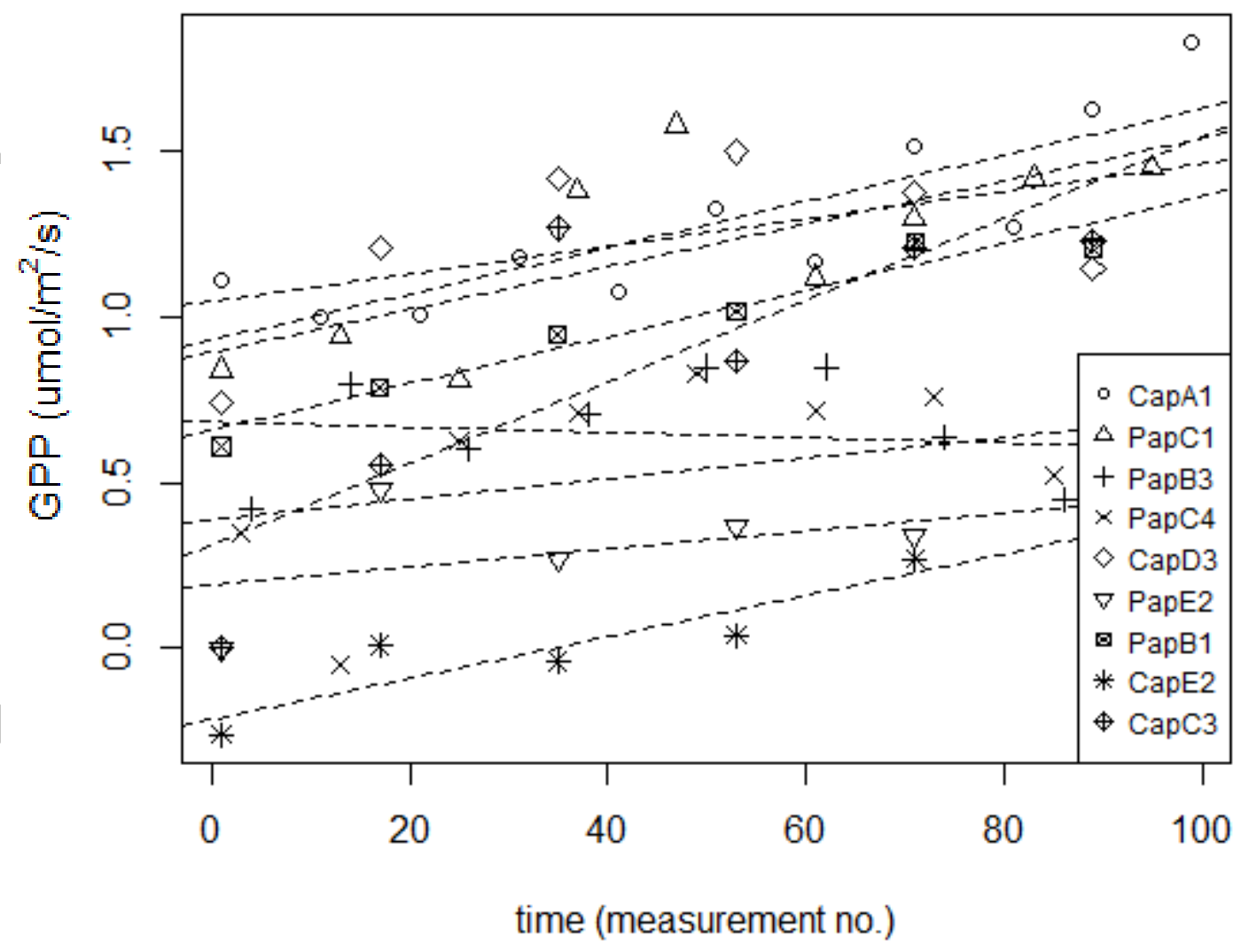

Figure A2 - GPP as a function of time for nine different Sphagnum samples. Measurement no. was used to indicate time, as measurements started at the same time each morning, and each sample took five minutes to complete measurements.

Table A2 -Each sample tested for PAR-time relationship, as shown in Figure A2. This table gives the slope of the regression line for each sample, the correlation between the PAR and GPP values, and the number of measurements taken.

\begin{tabular}{|l|l|l|l|}
\hline & slope & correlation & no. of measurements \\
\hline PapC1 & 0.0065 & 0.73 & 9 \\
\hline CapC3 & 0.0123 & 0.81 & 6 \\
\hline PapB1 & 0.0071 & 0.97 & 6 \\
\hline PapC4 & 0.0031 & 0.37 & 9 \\
\hline PapB3 & -0.0008 & -0.16 & 9 \\
\hline PapE2 & 0.0027 & 0.54 & 6 \\
\hline CapE2 & 0.0063 & 0.94 & 6 \\
\hline CapA1 & 0.007 & 0.85 & 11 \\
\hline CapD3 & 0.0041 & 0.5 & 6 \\
\hline
\end{tabular}

This article is protected by copyright. All rights reserved. 
The average slope value was 0.0054 , so the equation used was:

GPPr $=0.0054 \times$ measurement number

$\mathrm{GPP}=\mathrm{GPPm}-\mathrm{GPPr}+0.2$

1.4 was added to the PAR correction, and 0.2 to the time correction, in order to match the midpoint of GPP results across the dataset. Figure A3 compares the results from the time correction and the PAR correction for the nine samples used to compute the corrections.

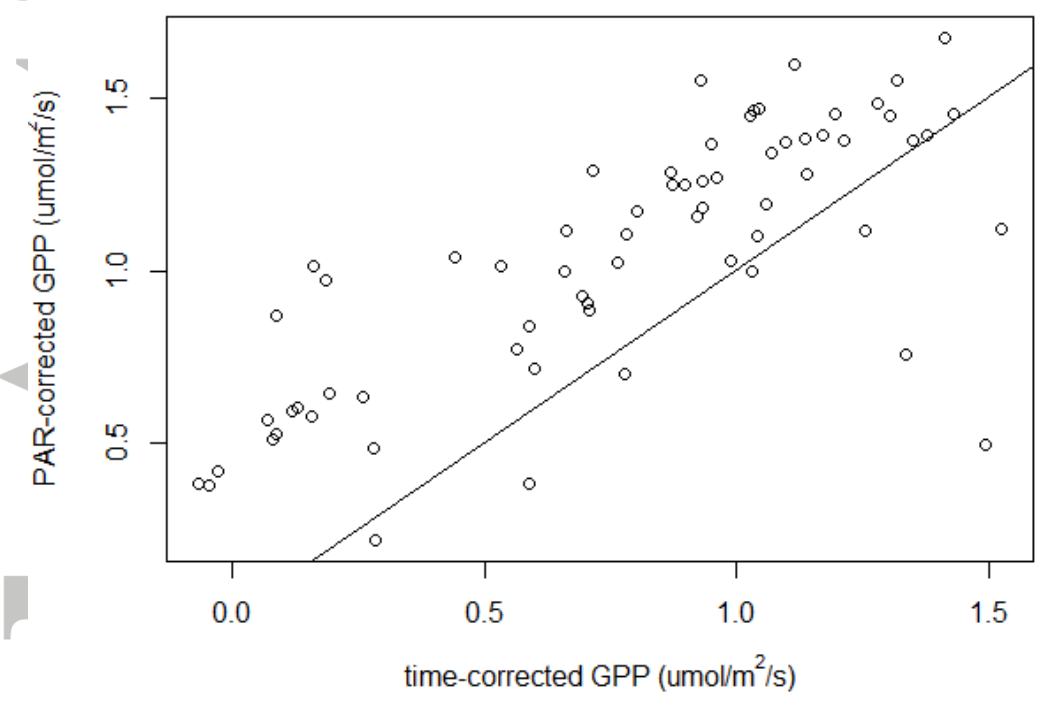

Figure A3 - PAR-corrected GPP plotted against time-corrected GPP for the nine tested samples. A 1:1 line is drawn.

Note that the order of samples on each day was randomised, and all significant trends were considered with respect to the control A, and the same correction was applied to all samples. 

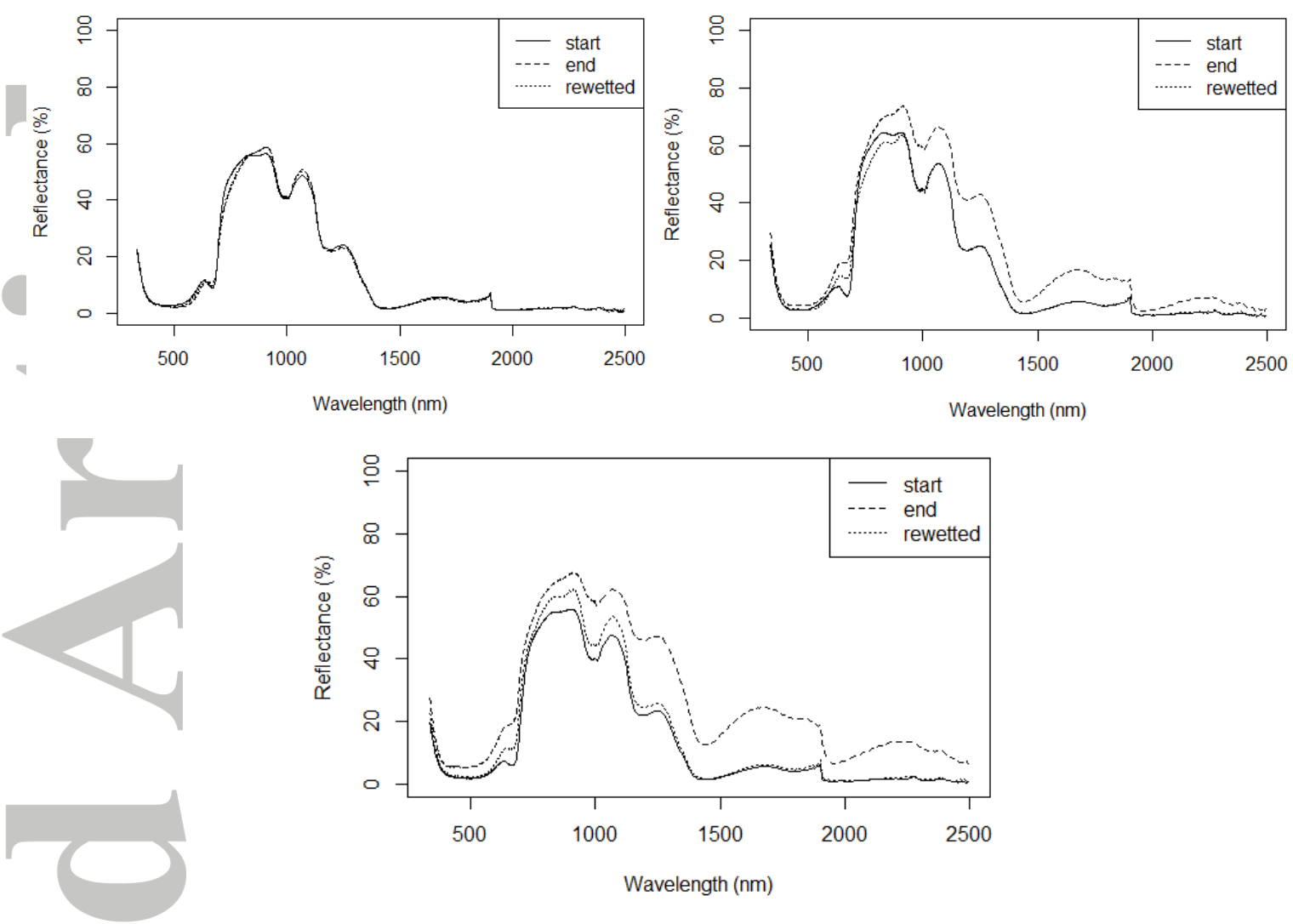

Figure A3-Spectral graphs at the start and end of the 80 day experimental period, and after rewetting. Top left: sample CapB1; top right: sample CapC1; bottom: sample CapD1.

Table A3 - Results from the tests; Kruskal-Wallis significant results shown ( $p<0.05$, no comment; $p<0.1$, moderate sig.). $\mathrm{N}=4$ for each species in each group. The measured variables are water $\mathrm{in} \mathrm{g} / \mathrm{g}$, GPP and Respiration in $\mu \mathrm{mol} / \mathrm{m}^{2} / \mathrm{s}$.

\begin{tabular}{|l|l|l|l|}
\hline Measured variable & Fligner-Killeen & Two-way ANOVA & $\begin{array}{l}\text { Kruskal-Wallis test with } \\
\text { Dunn's test }\end{array}$ \\
\hline Water-Start & Equal & No sig diff & \\
\hline Water-End & Equal & $\begin{array}{l}\text { Residuals non-normal } \\
\text { Group effect } \\
\text { No species effect } \\
\text { No interaction effect }\end{array}$ & $\begin{array}{l}\text { A to E } \\
\text { B to C,D,E }\end{array}$ \\
\hline Water-Rewetted & Equal & No sig diff & \\
\hline GPP-Start & Non-equal & No sig diff & $\begin{array}{l}\text { Desiduals normal } \\
\text { Group effect } \\
\text { No species effect } \\
\text { No interaction effect }\end{array}$ \\
\hline GPP-End & Equal & $\begin{array}{l}\text { Residuals normal } \\
\text { Group effect } \\
\text { No species effect } \\
\text { No interaction effect }\end{array}$ & E to A,B,C,D \\
\hline GPP-Rewetted & Equal & &
\end{tabular}




\begin{tabular}{|l|l|l|l|}
\hline R-Start & Equal & $\begin{array}{l}\text { Residuals normal } \\
\text { Group effect } \\
\text { Moderate sig species effect } \\
\text { No interaction effect }\end{array}$ & $\begin{array}{l}\text { A to E } \\
\text { C to E }\end{array}$ \\
\hline R-End & Equal & $\begin{array}{l}\text { Residuals normal } \\
\text { Group effect } \\
\text { No species effect } \\
\text { No interaction effect }\end{array}$ & $\begin{array}{l}\text { B to C } \\
\text { E to A, C, D } \\
\text { A to B moderate sig }\end{array}$ \\
\hline R-Rewetted & Equal & $\begin{array}{l}\text { Residuals normal } \\
\text { Group effect } \\
\text { No species effect } \\
\text { No interaction effect }\end{array}$ & $\begin{array}{l}\text { B to C,E } \\
\text { D to E }\end{array}$ \\
\hline NDVI-Start & Equal & $\begin{array}{l}\text { Residuals non-normal } \\
\text { No group effect } \\
\text { Species effect } \\
\text { No interaction effect }\end{array}$ & Cap to Pap \\
\hline NDVI-End & Equal & $\begin{array}{l}\text { Residuals normal } \\
\text { Group effect } \\
\text { Species effect } \\
\text { No interaction effect }\end{array}$ & $\begin{array}{l}\text { Cap to Pap } \\
\text { E to A, B, C }\end{array}$ \\
\hline NDVI-Rewetted & Equal & $\begin{array}{l}\text { Residuals normal } \\
\text { Group effect } \\
\text { Species effect } \\
\text { No interaction effect }\end{array}$ & $\begin{array}{l}\text { Cap to Pap } \\
\text { E to A, B, C, D }\end{array}$ \\
\hline
\end{tabular}



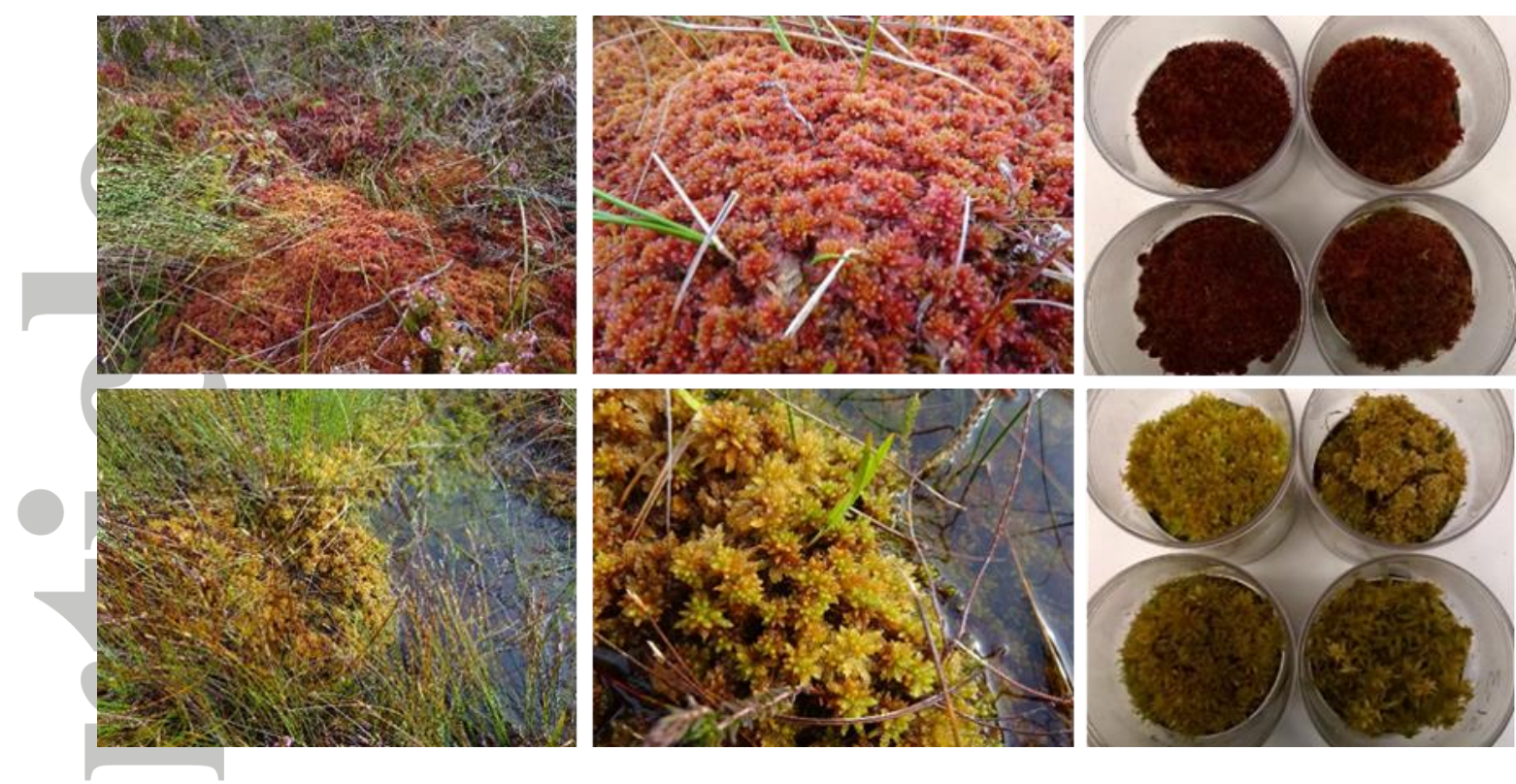

Figure 1-Clockwise from top left: $\mathrm{S}$. capillifolium in the field at sampling time, $\mathrm{S}$. capillifolium texture, S. capillifolium samples in the lab, S. papillosum samples in the lab, S. papillosum texture, S. papillosum in the field at sampling time.

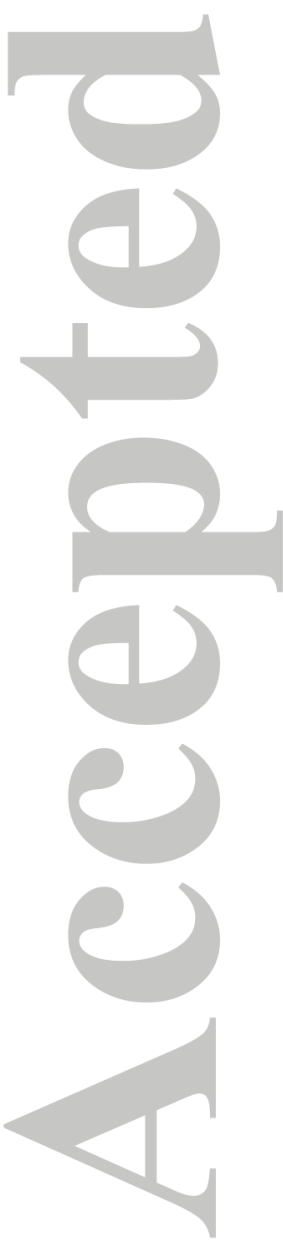




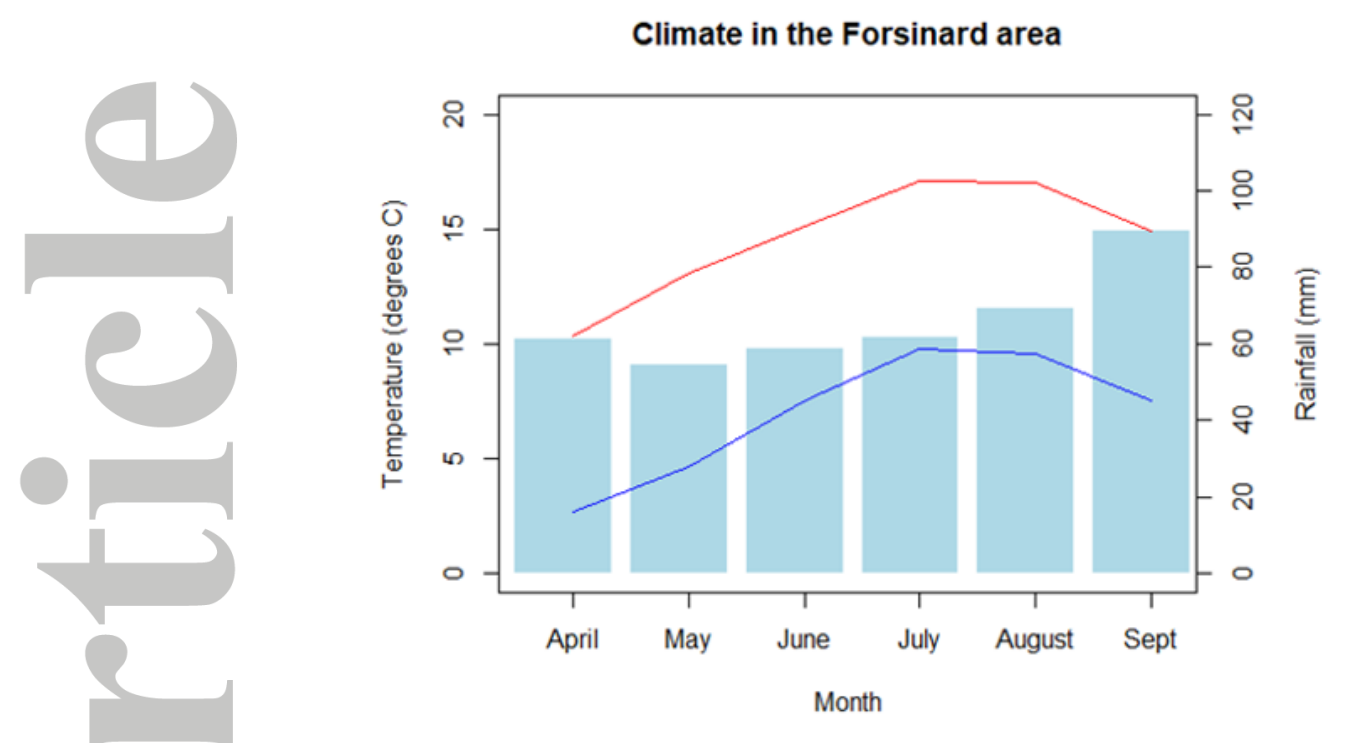

Figure 2- Climate in the Forsinard area, taken from 1981-2010 averages of the four nearest weather stations: Wick, John O Groats Airport, Kinbrace, Altnaharra SAWS, and Strathy East. Top line (red) gives daily maximum temperatures, lower line (blue) gives daily minimums. Bars give monthly rainfall.

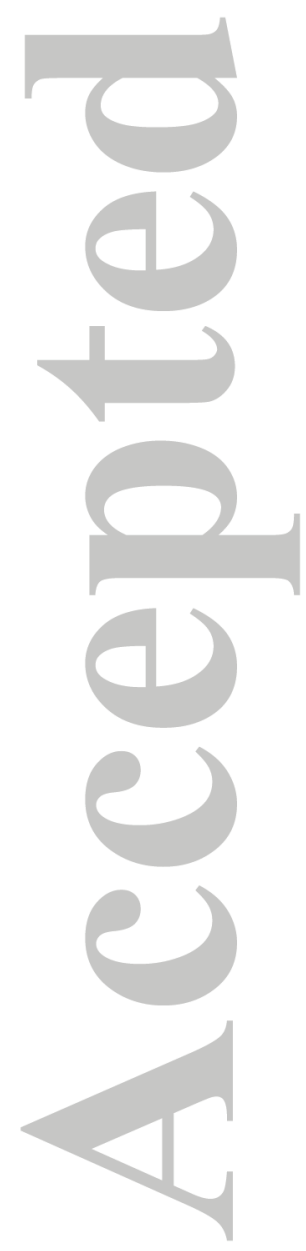




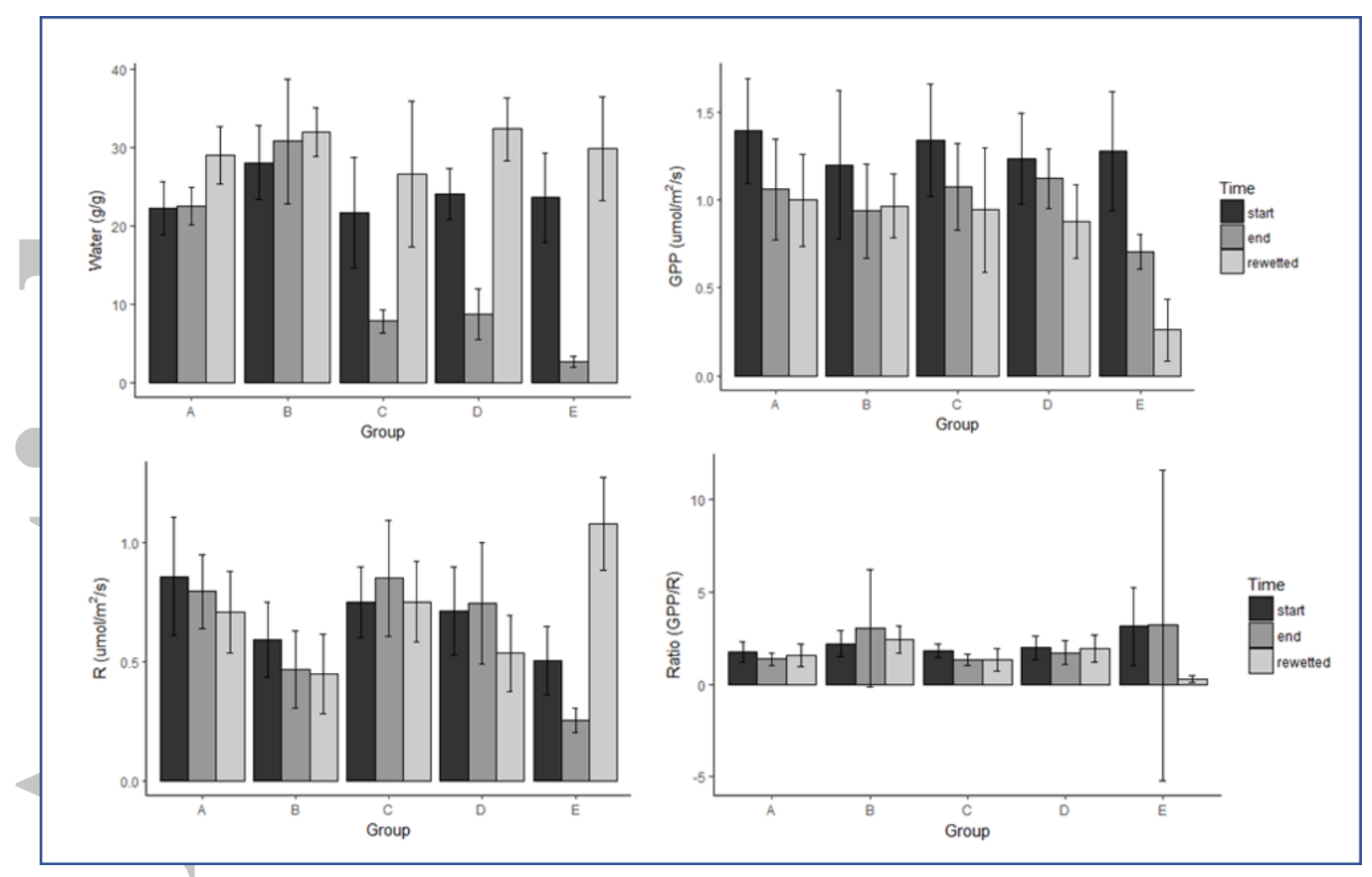

Figure 3 - Clockwise from top left: Water content ( $\mathrm{g}$ fresh weight/g dry weight); PAR corrected GPP; Respiration; Ratio of GPP/Respiration. Each graph shows the five groups at the start of the period, end of the watering regimes, and after rewetting. Error bars show the standard deviation of the group. 


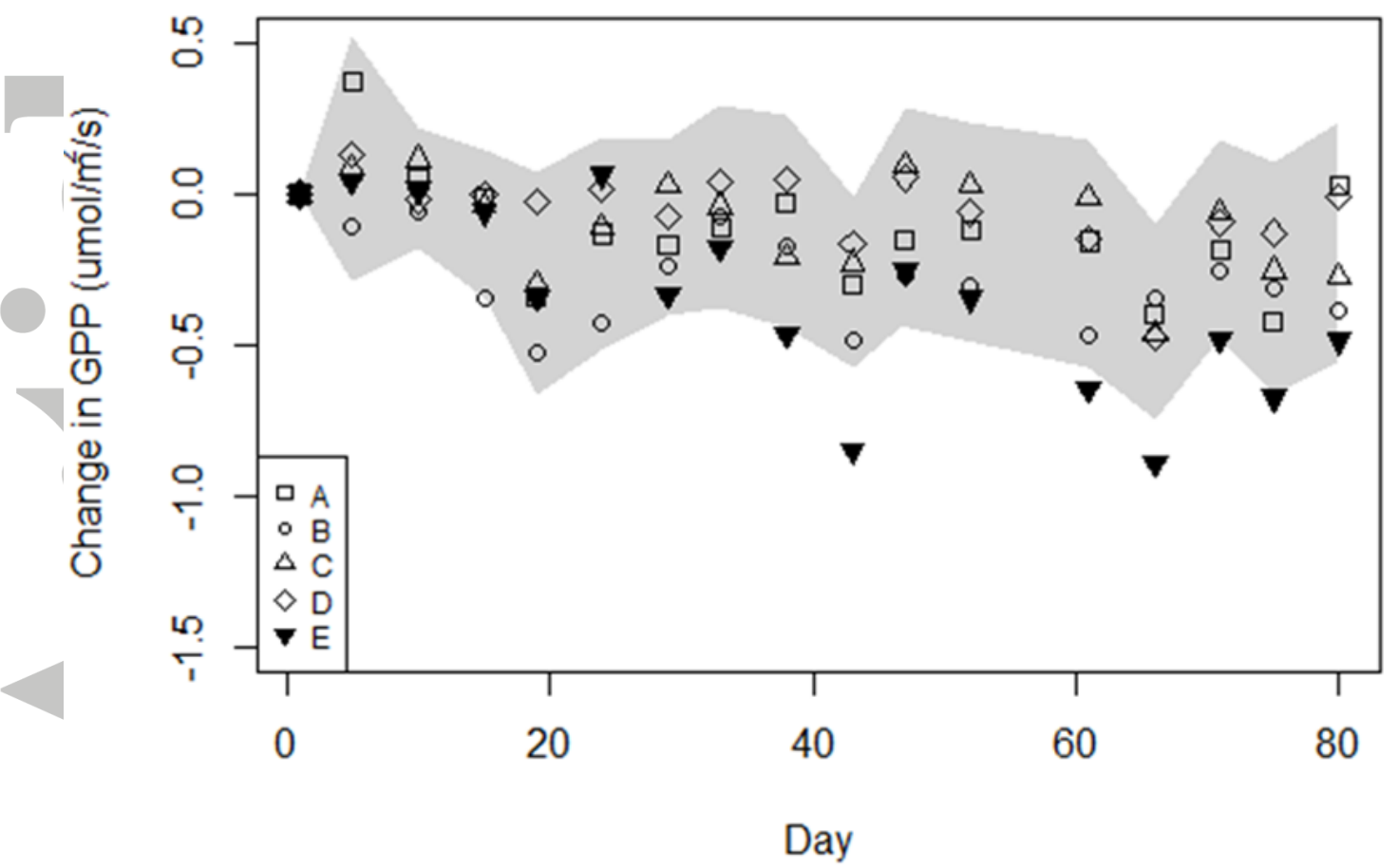

Figure 4 - The mean of each group change in GPP across the 80 days experimental period. Both species are included in the group means as there were no significant species differences in GPP. Grey area shows the standard deviation for groups A to D. 


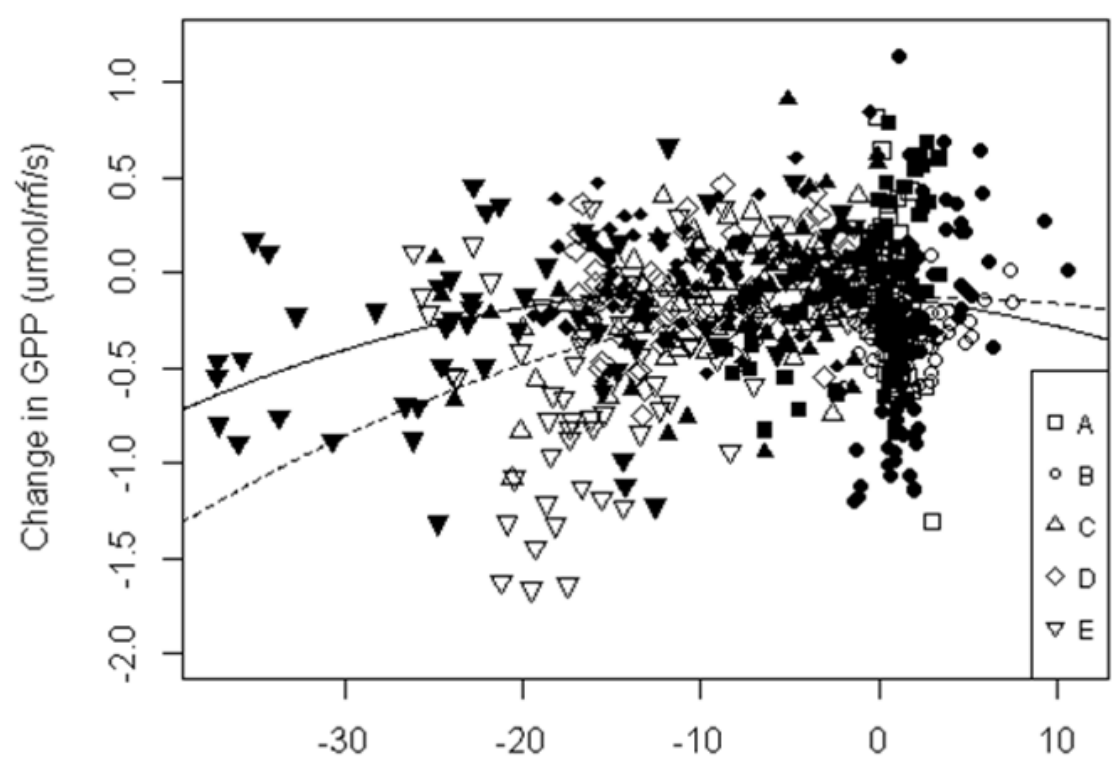

Change in water content $(g / g)$

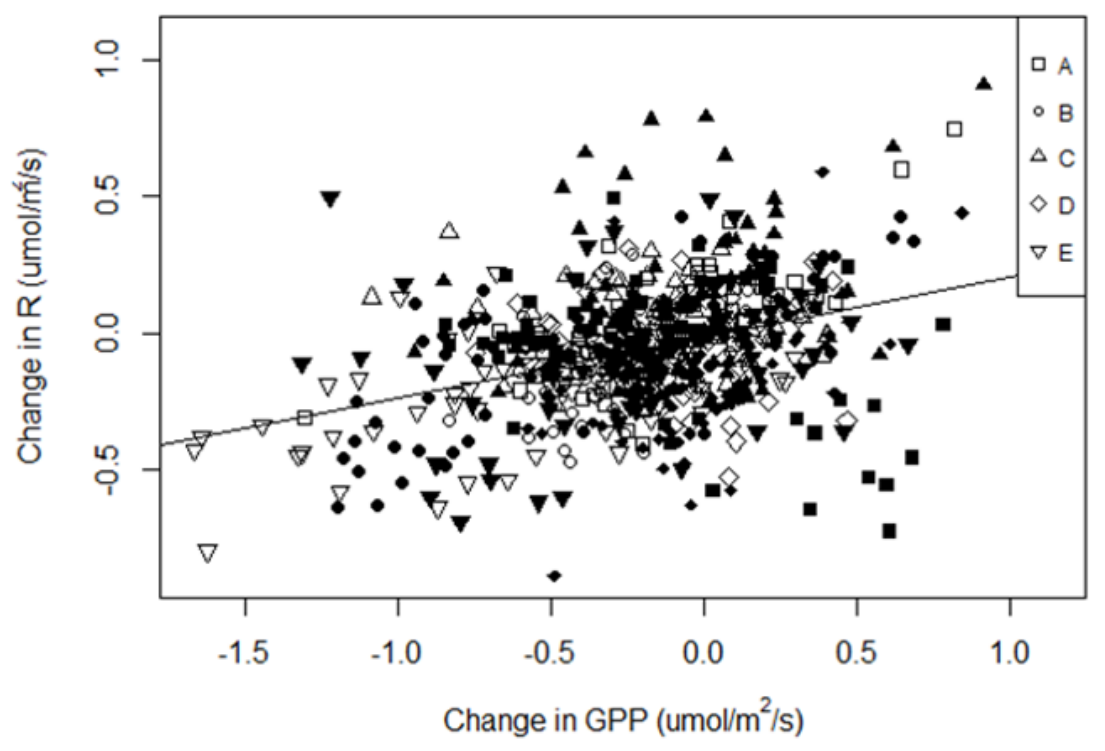

Figure 5 - Top: Change in GPP plotted against change in water content for the 80 days of watering regimes. Quadratic functions are fitted to each species, both significant at the $\mathrm{p}<0.05$ level, solid shows S. capillifolium, dotted shows S. papillosum. Bottom: Change in respiration plotted against change in GPP throughout the 80 days watering regimes. The linear model shows a significant relationship $(\mathrm{p}<0.05)$ between GPP and $\mathrm{R}$ for all samples, with the equation $y=0.22 x-0.015$ and adjusted $R^{2}$ value of 0.13 . In both graphs empty symbols show $S$. capilifollium, filled show $\mathrm{S}$. papillosum. 


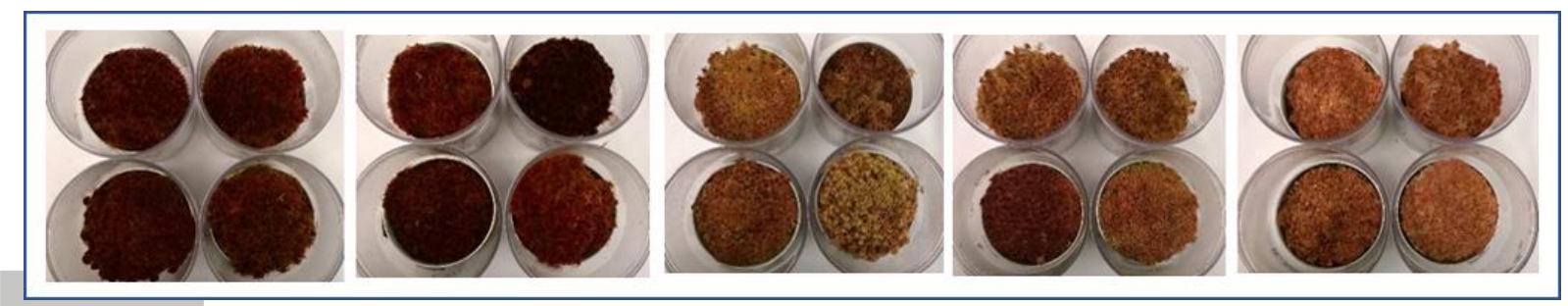

Figure 6 - photos showing S. capillifolium of groups A to E (left to right) at the end of the 80 day drying period. The photos illustrate the bleaching effect of reduced water content.
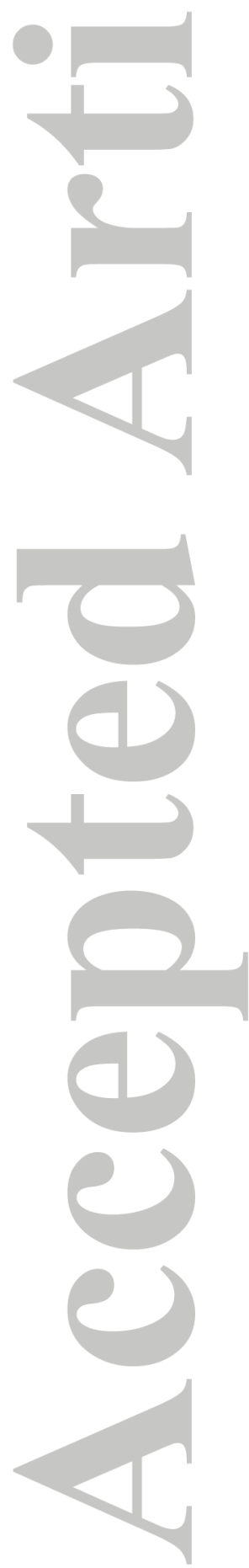


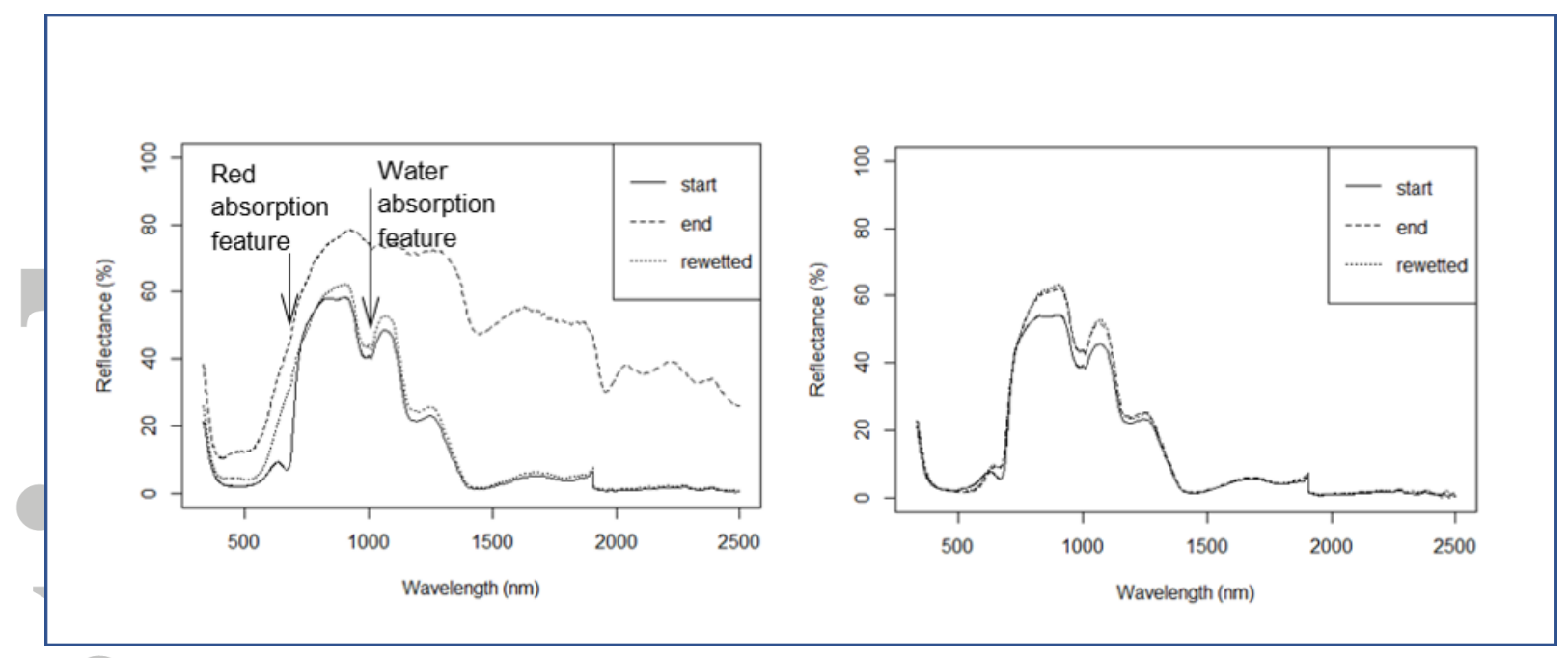

Figure 7 -Left: change in spectral reflectance in an S. capillifolium sample from total drought group E (sample CapE1) from the start of the 80 day experimental period (wet) to the end (dry), and also after rewetting. The increase in reflectance at all wavelengths in the dry sample is clearly obvious. Also note the lack of a red absorption feature (at approx. 650nm) and the water absorption trough (at approx. 1000nm) in the dry spectrum. The red absorption feature is still absent in the rewetted spectrum. Right: spectra of an S. capillifolium sample from control group A (sample CapA1), showing very little change. Spectral reflectance graphs for samples from groups B, C, and D are shown in Appendix 2. 


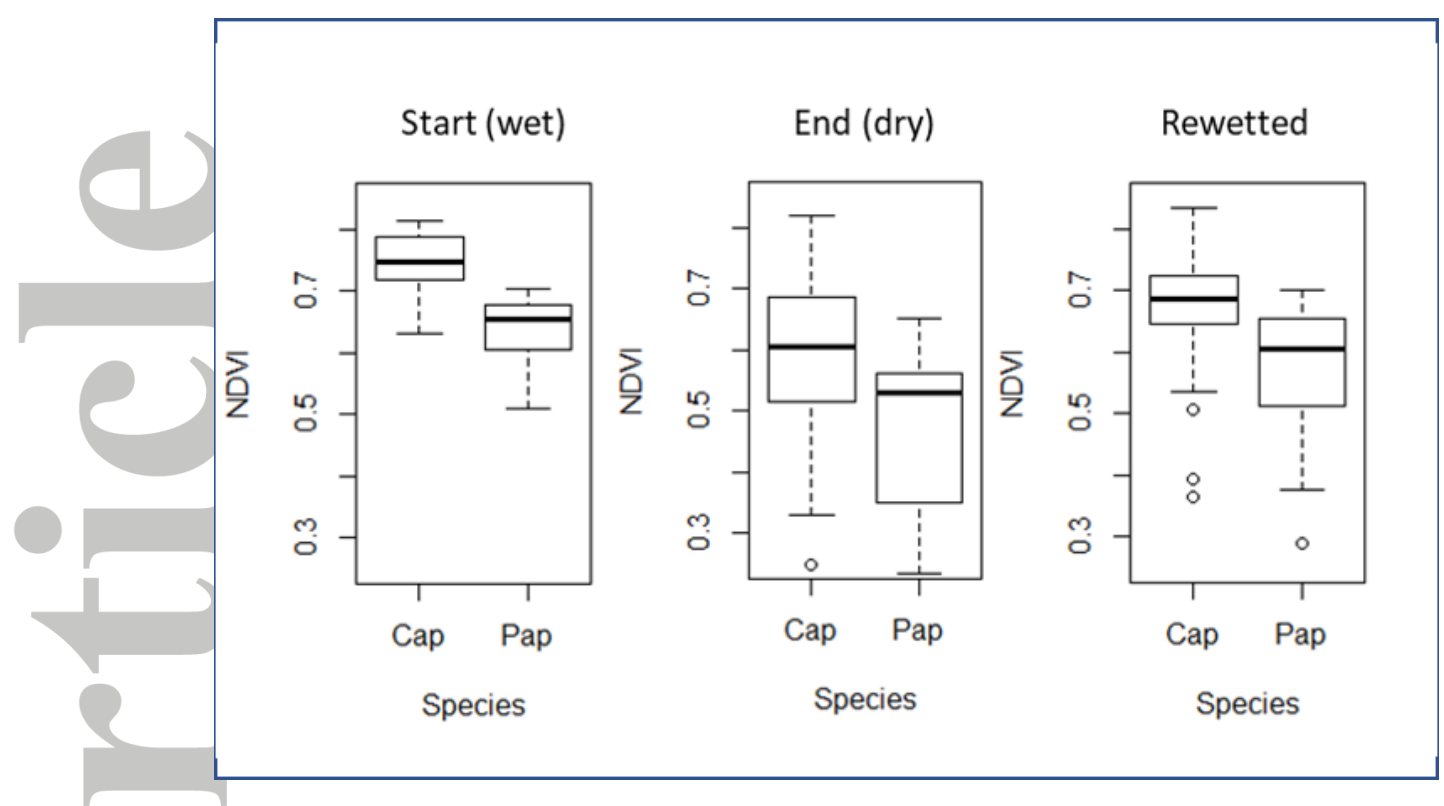

Figure 8 - S. capillifolium had higher NDVI values than S. papillosum throughout the experiment.

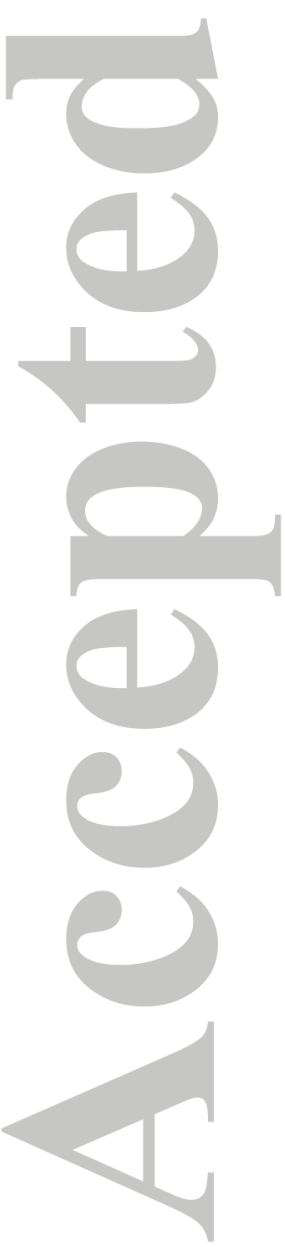




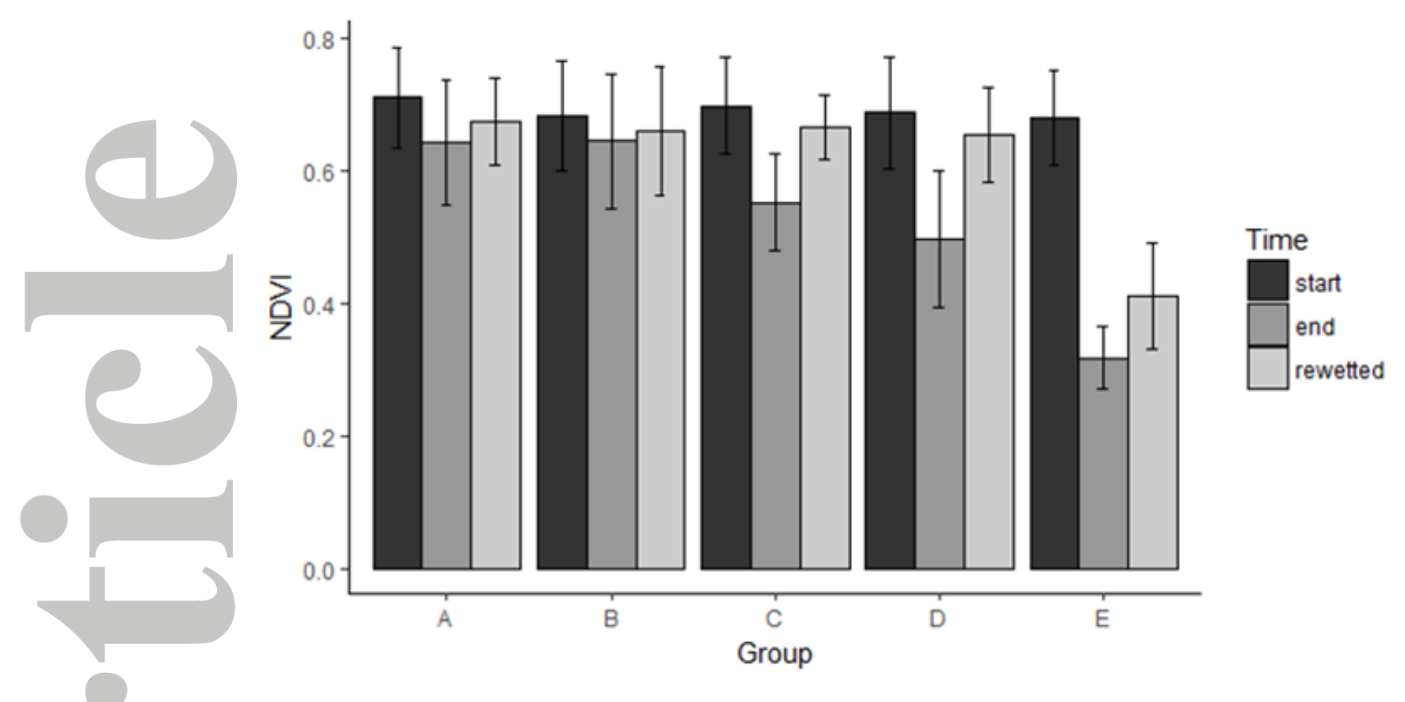

Figure 9 - NDVI values for each of the five groups at the start and end of watering regimes, and after rewetting.
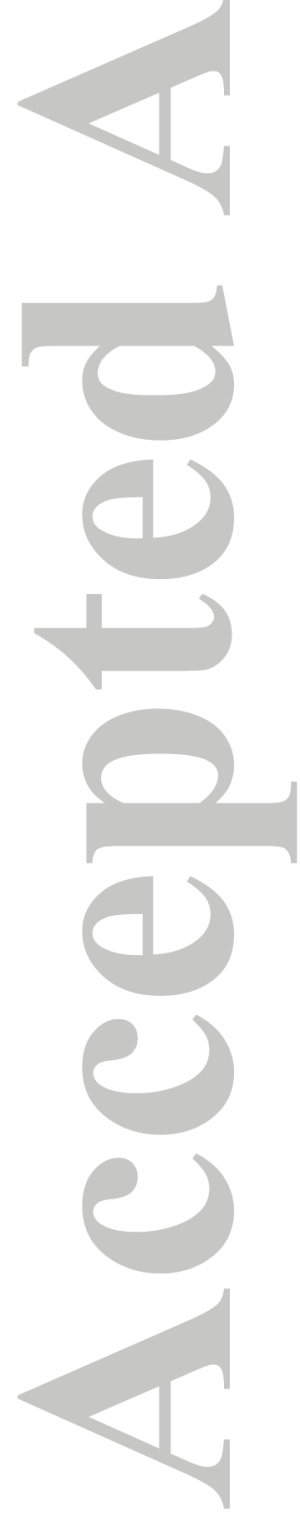


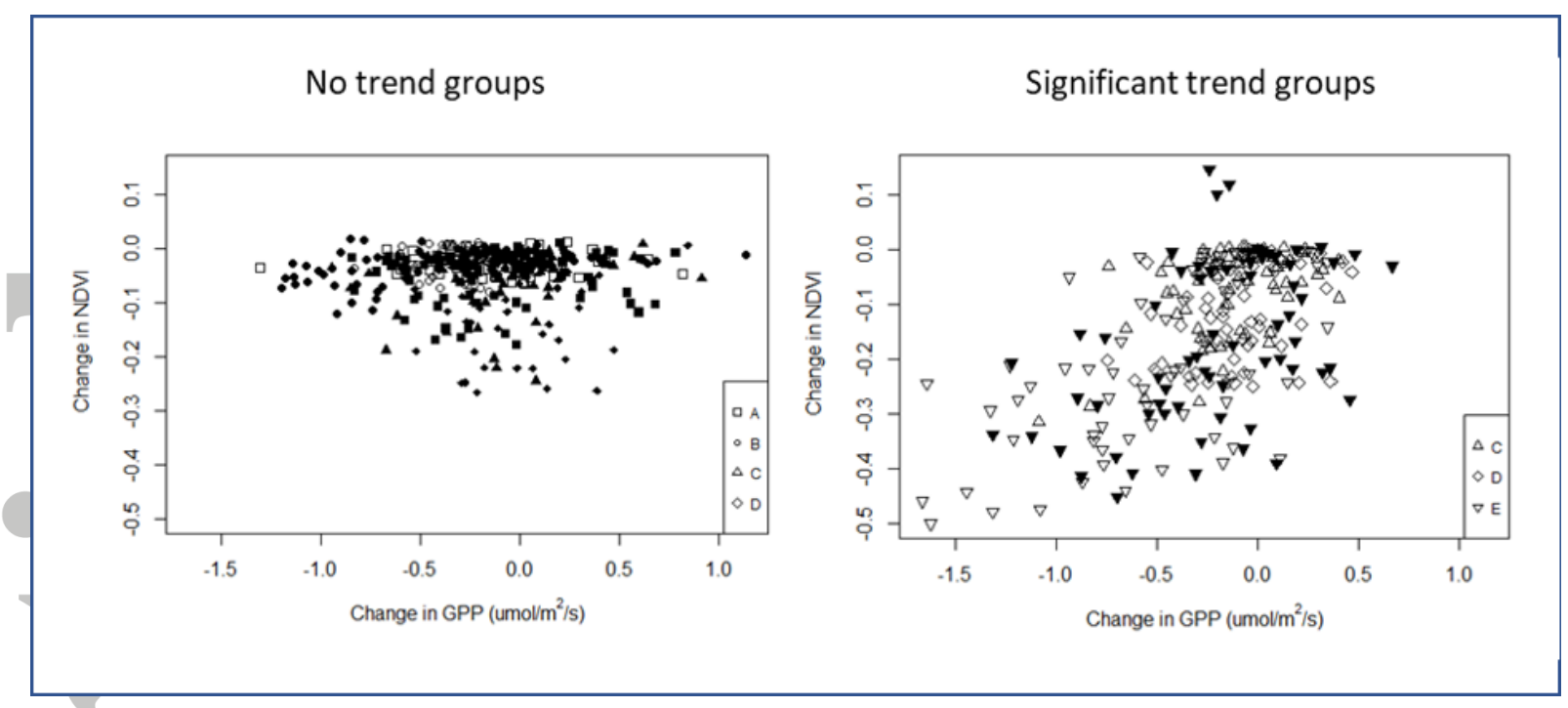

Figure 10 - Change in NDVI plotted against change in GPP throughout the 80 days experimental regimes. Groups A and B show no trend in either species (actually group B in S. papillosum does give a significant linear model, but the slope is so small that it is almost nonexistent), groups $\mathrm{C}$ and D show a trend in S. capillifolium but not S. papillosum, group E shows a trend in both. The groups which show no trend are plotted in the left-hand graph, whilst those with a significant trend are shown in the right-hand graph. Unfilled symbols represent $\mathrm{S}$. capillifolium, filled represent $\mathrm{S}$. papillosum samples. 
Table 1 - The five rainfall simulations treatment groups A to E, with precipitation frequency and amount over the 12 week experiment shown. Each group included four samples of $S$. capillifolium and four of S. papillosum.

\begin{tabular}{|l|l|l|}
\hline Group & $\begin{array}{l}\text { Precipitation } \\
\text { amount (ml per } \\
\text { fortnight) }\end{array}$ & $\begin{array}{l}\text { Precipitation } \\
\text { frequency (per } \\
\text { fortnight) }\end{array}$ \\
\hline A (control) & 120 & 6 \\
\hline B & 120 & 3 \\
\hline C & 60 & 3 \\
\hline D & 60 & 6 \\
\hline E (total drought) & 0 & N/A \\
\hline
\end{tabular}


Table 2 - Previous studies determining optimum water content for carbon function in different Sphagnum species, and measuring whether Sphagnum GPP recovered after desiccation and rewetting.

\begin{tabular}{|c|c|c|c|c|c|c|}
\hline Study & Species & $\begin{array}{l}\text { Optimum water } \\
\text { content }\end{array}$ & $\begin{array}{l}\text { Minimum water } \\
\text { content }\end{array}$ & $\begin{array}{l}\text { Rewetting } \\
\text { period }\end{array}$ & Recovery of GPP? & Notes \\
\hline Current study & $\begin{array}{l}\text { S. capillifolium } \\
\text { S. papillosum }\end{array}$ & $\begin{array}{l}15.8 \mathrm{~g} / \mathrm{g}(8.9-21.9) \\
27.5 \mathrm{~g} / \mathrm{g}(15.7- \\
41.5)\end{array}$ & $\begin{array}{l}80 \text { days drought, } \\
2.2 \mathrm{~g} / \mathrm{g}\end{array}$ & 30 days & No & Sphagnum cores, lab \\
\hline $\begin{array}{l}\text { Robroek et al., } \\
2009\end{array}$ & $\begin{array}{l}\text { S. rubellum } \\
\text { S. magellanicum } \\
\text { S. cuspidatum }\end{array}$ & $\begin{array}{l}\text { Approx. } 20 \mathrm{~g} / \mathrm{g} \\
\text { Approx. } 28 \\
\text { Approx. } 30\end{array}$ & $\begin{array}{l}23 \text { days drought, } \\
\text { water table } 10 \mathrm{~cm} \\
\text { below Sphagnum } \\
\text { surface }(6 \mathrm{~g} / \mathrm{g})\end{array}$ & 16 days & $\begin{array}{l}\text { Yes, but not to pre- } \\
\text { drought levels }\end{array}$ & $\begin{array}{l}\text { Intact Sphagnum cores, } \\
\text { lab }\end{array}$ \\
\hline $\begin{array}{l}\text { Van Gaalen et } \\
\text { al., } 2007\end{array}$ & S. teres & $8-9 \mathrm{~g} / \mathrm{g}$ & $\begin{array}{l}\text { 2-3 hrs, approx. } 5 \\
\text { g/g }\end{array}$ & 10 mins & No & $\begin{array}{l}\text { Thin samples from } \\
\text { moss lawn, lab }\end{array}$ \\
\hline $\begin{array}{l}\text { Adkinson and } \\
\text { Humphreys, } \\
2011\end{array}$ & $\begin{array}{l}\text { Mixed } \\
\text { hummock } \\
\text { species } \\
\end{array}$ & $5-13 \mathrm{~g} / \mathrm{g}$ & & & & $\begin{array}{l}\text { Capitula water content, } \\
\text { mat flux, field }\end{array}$ \\
\hline $\begin{array}{l}\text { Schipperges and } \\
\text { Rydin, } 1998\end{array}$ & $\begin{array}{l}\text { S. fuscum } \\
\text { S. papillosum } \\
\text { S. magellanicum } \\
\text { S. balticum } \\
\text { S. cuspidatum }\end{array}$ & $\begin{array}{l}370-1300 \% \text { dry } \\
\text { wt. } \\
620-2550 \% \\
700-1550 \% \\
600-1500 \% \\
400-1450 \%\end{array}$ & $\begin{array}{l}\text { Capitula below } 100 \\
\%, 12 \text { days } \\
\text { (Experiment } 3)\end{array}$ & 12 hrs? & No & Capitula, lab \\
\hline $\begin{array}{l}\text { McNeil and } \\
\text { Waddington, } \\
2003\end{array}$ & S. capillifolium? & $11.3-26.7 \mathrm{~g} / \mathrm{g}$ & $6 \% \mathrm{VMC}, 7$ days & 20 days & Yes & Moss cushion, lab \\
\hline
\end{tabular}




\begin{tabular}{|l|l|l|l|l|l|l|}
\hline $\begin{array}{l}\text { Titus, Wagner, } \\
\text { \& Stephens, } \\
1983\end{array}$ & $\begin{array}{l}\text { S. fallax } \\
\text { S. } \text { nemoreum }\end{array}$ & $\begin{array}{l}\text { Approx. 6-11 g/g } \\
\text { Approx 9 g/g }\end{array}$ & & & Capitula, lab \\
\hline Nijp et al., 2014 & $\begin{array}{l}\text { S. fuscum } \\
\text { S. majus } \\
\text { S. balticum }\end{array}$ & & 17 days drought & 11 days & $\begin{array}{l}\text { S. fuscum full } \\
\text { recovery; } \text { S. majus } \\
\text { and S. balticum little } \\
\text { recovery }\end{array}$ & $\begin{array}{l}\text { Sphagnum cores, lab } \\
\text { Wagner \& Titus, } \\
1984\end{array}$ \\
\hline
\end{tabular}

